\title{
Progress in Health around the World
}

\section{Citation}

Canning, David. 2012. Progress in health around the world. The Journal of Development Studies 48, no. 12: 1784-1798. doi:10.1080/00220388.2012.663907.

\section{Published Version}

doi:10.1080/00220388.2012.663907

\section{Permanent link}

http://nrs.harvard.edu/urn-3:HUL.InstRepos:33730184

\section{Terms of Use}

This article was downloaded from Harvard University's DASH repository, and is made available under the terms and conditions applicable to Other Posted Material, as set forth at http:// nrs.harvard.edu/urn-3:HUL.InstRepos:dash.current.terms-of-use\#LAA

\section{Share Your Story}

The Harvard community has made this article openly available.

Please share how this access benefits you. Submit a story.

Accessibility 


\title{
DNE DEMOGRAPHY OF AGING
}

\author{
Working Paper Series
}

\section{Progress in Health around the World}

\author{
David Canning \\ October 2011 \\ PGDA Working Paper No. 80 \\ http://www.hsph.harvard.edu/pgda/working.htm
}

The views expressed in this paper are those of the author(s) and not necessarily those of the Harvard Initiative for Global Health. The Program on the Global Demography of Aging receives funding from the National Institute on Aging, Grant No. 1 P30 AG024409-06. 


\title{
Progress in Health around the World
}

\author{
David Canning \\ Harvard School of Public Health \\ October 2011
}

\begin{abstract}
Health is a key component of human development. This paper looks at how health is measured, and the convergence of health across countries. We argue that health measures should account for illness as well as mortality, but in practice life expectancy as a reasonably proxy for population health. While health is improving we see two distinct groups of countries in the data, clustering around different long run steady states. Many countries have experienced large health gains without prior income gains and in countries not affected by HIV/AIDS the last 40 years have been a success story in terms of health.
\end{abstract}

Keywords: health, life expectancy, human development.

JEL classification: I10, I30.

The Author is Richard Saltonstall Professor of Population Sciences at the Harvard School of Public Health E-mail: dcanning@hsph.harvard.edu

Comments should be addressed by email to the author(s).

The author is grateful to the United Nations Development Office for comments on an earlier draft of this paper. 


\section{Health in Human Development}

There is wide spread agreement that health is an important component of human development. Health was identified as a component of human development in the Human Development Report 1990 (United Nations Development Program 1991) and is a central part of the Human Development Index. The World Bank has shifted from an emphasis on promoting economic growth (e.g. Commission on International Development, 1969) to include a focus on health, education, and social exclusion (see World Development Report 2001). The Millennium Development Goals, adopted at the Millennium Summit of the United Nations in September 2000 focused on poverty, mortality, education, health, gender equality and environment as the key measures of development.

More recently The Commission on the Measurement of Economic Performance and Social Progress (2009) put forward eight distinct spheres of wellbeing in addition to consumption and wealth: health, education, personal activity, political voice and governance, social connectedness, environmental conditions, personal insecurity, and economic insecurity. It also argued for a focus on inequality in these indicators as well measures of their average levels.

While there seems to be general agreement that health is an important component of human development there is an issue about how exactly we should measure health. To some extent this is a question of the conceptual underpinning of the development measure we seek. Our theory of what development is, and of well being, should dictate the appropriate health measure. On the other hand we have the consideration that at present we only have few internationally comparable measures of health and in practice must base comparisons on these. While it is true we are limited in the set of health variables we can use, it is useful to discuss how 
well these measures correlate with the more meaningful underlying measure of health we would like to use.

This gap between theory and measurement is partly a matter of a conceptual gap - the health measure we use may be trying to measure something that is different for the measure we would wish in theory. However we also have measurement error; we may not perfectly capture the construct we are trying to capture.

The measure of health currently used in the Human Development Index is life expectancy. The period 1970-2005 has seen large improvements in life expectancy in most countries and a convergence in life expectancy, with countries that had lower life expectancy in 1970 seeing larger gains in life expectancy subsequently. However, when we look at the data in more detail a more complex picture emerges. Instead of uniform convergence to a high level of life expectancy, there appear to be two separate groups of countries. One group has low life expectancy while the other has high life expectancy. Among the high life expectancy countries we see modest and fairly uniform gains in life expectancy over time. Among countries with low initial life expectancy increases in life expectancy are not a uniform and smooth catch up. Rather some countries that initially have low life expectancy seem to jump to join the high life expectancy regime, while others stagnate with low or little in the way of life expectancy gain, and sometimes even falling life expectancy.

As well as the general trends outlines above we have some countries which are outliers to the process. One set of outliers are the Sub-Saharan African countries with high levels of HIV/AIDS. The general patterns of pattern relative failure of countries with initially low life expectancy is exacerbated by the large number of HIV/AIDS deaths in Sub-Saharan but the phenomenon is not entirely due to HIV/AIDS; these countries are outliers to the process outlined 
above. The countries with high prevalence rates of HIV have seen little in life expectancy improvement and indeed some have seen absolute declines relative to 1970 levels. The other area in which there has been a relative failure to improve life expectancy has been in the former Soviet Republics. In addition we have a small number of countries. In contrast to these we have a number of success stories, countries with life expectancy gains far in excess of our model's predictions and sometimes involving a jump to low level health regime to the high level regime.

We also discuss the interrelationship between health and income. Income per capita is also part of the human development index and across countries higher levels of health and income go together. However the relationship is not close enough to take one as a proxy measure of the other. In addition, over the years 1970-2005 we see much larger improvements in health around the world than we would expect based solely on the increases in income over the period. Countries, even very poor countries, can improve their population health using direct health interventions even when incomes are not rising. It is important to realize that health improvements can be achieved with first waiting for income to rise.

Overall we have a fairly good picture of achievement in health. In most countries life expectancy has risen and the relatively faster rise in countries with initially low levels of health means that in these countries their human development index, relative to the leading country, will be rising. The great worry is the health crisis, particularly in Sub-Saharan Africa, being brought about by the high prevalence of HIV/AIDS. This is undoing significant gains that were being made up until 1990 and makes it difficult to substantial future health gains in these countries. 


\section{The concept of health}

Life expectancy is the health measure used in the Human Development Index. We now turn to the issue of whether life expectancy is the right measure of population health on conceptual grounds. Mathers et al. (2003) also consider this issue. It is clear that a longer life span is preferable to a shorter lifespan, but the quantity of lifespan says nothing about the quality of life or health while alive. There are a number of approaches to adjusting life years lived by health status to get a better measure that accounts for illness. One approach is to use quality adjusted life years (QALYs) where individuals express their preferences by valuing the quality of a life year lived in a state of ill health as the fraction of a year lived in full health that would give them the same utility. Another is to use disability adjusted life years (DALYs) where a life year lived with disability is considered equal to a fraction of a year lived in full health, with the adjustment being made by an expert panel.

To some extent these two approaches to adjusting life years for ill health represent different ways of thinking about of welfare. One way is to use a utilitarian social welfare function. In this approach social welfare is defined as the sum of individual utilities. In a utility approach the right way to weight goods is in terms of individuals' willingness to trade them off for other things, depending on how much they add to utility. This leads to using QALYs. However, in the capabilities approach to measuring development we can think of welfare as being measured by the size of the choice set rather than the utility of what is chosen. In the capabilities approach we can think of healthy life span as a basic constraint that limits people's choice, and we want to measure the objective size of the choice set, independently of how people value the choices. This approach leads to a preference to use DALYs. 
A related issue is that QALYs depend on individual tradeoffs and the estimated QALY adjustment for a particular disability may vary between countries. If this is the case two countries with the same level of disability may have different estimates of their health status if people in the two countries value a year of life lived in disability (in terms of life years lived in full health) differently. It seems undesirable that countries with the same objective measures of health should be ranked differently in terms of welfare because of different preferences; we should therefore establish worldwide average values of the QALY adjustment related to each disability. This is difficult to do, and requires widespread surveys of preferences, while DALY adjustments have been already been set for each disability.

In order to get a single measure of population health including ill health as well as death, we can calculate healthy life expectancy by weighting years lived in disability as a fraction of a year lived in full health, using the DALY approach. To do this we need data on mortality and also the prevalence of disease and the frequency of each type of disability associated with each disease. The World Health Report 2004 (World Health Organization 2004) provides data on life expectancy against healthy life expectancy for 192 countries in 2002 . There is a close association between the two measures, with healthy life expectancy rising with life expectancy. A regression of healthy life expectancy, HL, on life expectancy, L, using this data gives

$$
\begin{gathered}
\mathrm{HL}=-3.859+0.936 \mathrm{~L} \\
(0.424) \quad(0.006) \\
N=192 \quad \mathrm{R}^{2}=0.991
\end{gathered}
$$

where we have standard errors of the estimates in parentheses. 
The intercept is significantly different from zero and the coefficient on life expectancy is significantly lower than one. This implies that healthy life expectancy is not simply a proportion of life expectancy. For example, according to this linear relationship when life expectancy is 40 , then healthy life expectancy is 33.6 and the proportion of years in ill health is 0.16 . In contrast, when life expectancy is 70 then healthy life expectancy is 61.6 so the proportion of years in ill health is 0.12 . Figure 1 plots life expectancy against the fraction of lifetime lived in disability and shows that the fraction of life spent in disability is relatively constant across countries with life expectancy below 60, but for countries where life expectancy is above 60 years the proportion of years in disability appears to decline as life expectancy rises. This relationship is investigated further in the web appendix.

What we see in the data is that at high levels of life expectancy there is a "compression of morbidity", longer life spans are associated with a compression of the relative and perhaps even absolute number of years spent disabled. In most developed countries we have time series of this compression of morbidity (Fries, 2003). When life expectancy increases, healthy life expectancy increases more than proportionately, compressing the number of years lived with disability into a shorter fraction of the lifespan. This means that life expectancy increases in developed countries are generally very good news since they go hand in hand with greater healthy life expectancy and delays in the average age at which disability occurs. Unfortunately we lack similar time series evidence on how expected years in disability changes when life expectancy increases in developing countries. The cross-country evidence, shown in web appendix, Figures A1 and A2, points to the expected age of onset of disability rising proportionately with life expectancy in these countries making life expectancy a fairly good proxy for healthy life expectancy. 
In cost effectiveness studies in which health gains are measured in QALYs or DALYs we usually discount gains to future life expectancy by a social discount rate (often a rate of $3 \%$ per annum is used, the real rate of interest on money). We could apply the same logic to measures of life expectancy at birth and argue that survival at birth, which comes in the immediate future, is more valuable than survival at older ages which comes in the distant future. However discounting in this way has several problems. Firstly we may not want to discount health at the same rate as money, and secondly it is it unclear that the discount rate used by individuals in deciding between present and future consumption is appropriate as social discount rate for comparing across generations born at different times (see Kaplow 2007 for a discussion of these issues).

In addition, life expectancy is not measured for a cohort born today over its future. It is actually a synthetic measure constructed from current period age specific mortality rates, and is the life span a person would expect if they were exposed to this age specific mortality. If we think of life expectancy simply as a summary statistic capturing current age specific mortality rates in a single number, there is no need to discount. However thinking of it as a summary measure of current mortality rates does raise the issue that it is more sensitive to changes in the infant mortality rate than to changes in mortality at older ages, since the "cost" of a death in terms of life expectancy foregone declines with age.

There is also the issue of inequality in life spans. A particular level of life expectancy can represent very different age specific mortality patterns. We could think of the variation in life spans as undesirable inequality if different life spans are identified with different groups in the population. Alternatively if everyone has the same life expectancy the different life spans actually experienced could be viewed as undesirable risk (Edwards, 2008). In either case we 
might want a measure that considers not just life expectancy but also the spread of life span outcomes experienced by the population. Penalizing the spread of life span outcomes introduces something that looks very like time discounting since gains in life span at high levels of life span are less valuable than gains at low spans, though now the "discount rate" can be thought of as a measure of social aversion to inequality or a measure of risk aversion. However it should be noted that the issues of inequality and risk cannot really be dealt with in one dimension of wellbeing alone. When we consider inequality and risk we will be concerned with the joint distribution of health, income and education, since the welfare impact of deprivation are unlikely to be a simply additive.

In addition to the issue of getting the right measure of health there is the issue of how health should be weighted in constructing the human development index. At present health, income and education get equal weights on one third each. If we take a social welfare approach to measuring human development we can ask how people value health improvements in terms of money units to get a sense of the relative importance of health and income in welfare. Becker, Philipson, and Soares (2005) estimate the money value of health improvements in each country based on estimates of willingness to pay for additional life years (Viscousi and Aldy 2003). They find that the value of life expectancy improvements between 1960 and 2000 were, on average, about the same as the value of income improvements. This implies that we should weight a countries health improvements roughly equally with is income improvements when thinking about total welfare and is in line with the current weighting of income and health in the human development index. 


\section{Estimates of Life Expectancy}

The human development index currently uses life expectancy as its measure of health. In this section we assume that life expectancy is the right measure and ask how well it is measured by current statistics. In theory, life expectancy can be calculated directly from age specific mortality rates. However when direct measures of age specific mortality are not available or are unreliable, there are also indirect methods of estimating life expectancy. Demographic indicators such as population growth rates, and the age distribution, are closely linked to mortality rates and life expectancy and data on such demographic indicators can be used to make inferences on the level of life expectancy. The United Nation's constructs reasonable estimates of life expectancy that are consistent both with the direct evidence and with indirect indicators, using information from a variety of data sources in each country.

Measurement of mortality rates and demographic indicators can be based on vital registration data, age distributions in the census, and nationally representative survey information on infant mortality and deaths of other family members. All of these data sources have potential problems, due, for example, to under-reporting of deaths in vital registration, under-enumeration of the population and age misreporting in census data, and survey data may suffer from error due to small sample sizes. The complete set of estimates of life expectancy across countries and over time includes some interpolated or extrapolated data, particularly prior to 1980 (Bos, Vu, Stephens, Patience, 1992).

The introduction of the World Fertility Surveys in the 1970s, which were followed by the Demographic and Health Surveys from the mid 1980s onwards, have led to improved estimates of infant and under five mortality in many developing countries. Data on adult mortality rates are often less reliable in these countries (Hill 2003). When the availability of relevant direct data is 
limited, model life tables are used to provide indirect estimates life expectancy. For example when there is data only on infant mortality available model life tables can be used to impute life expectancy. This means that life expectancy estimates for developing countries are sometimes based on a simple transformation of their infant mortality rates (Deaton 2007). These transformations have changed over the last few years to take into account the change in age specific mortality pattern due to HIV/AIDS.

The underlying data on infant and under five mortality rates from household surveys may be less reliable if they are used to estimate child mortality retrospectively. While questions on births and child survival asked of mothers (conditional on these mothers still being alive) over the last five years are usually thought to be reasonable, calculating infant mortality rates on longer recall periods may be subject to recall bias. In the web appendix we show as examples differing estimates of under five mortality for Guatemala and Nigeria from surveys and vital registration and discuss the reasons for these differences.

Issues of methods and measurement in estimating life expectancy are discussed in detail in Lopez et al. (2003). Even the best estimates are subject to a range of uncertainty and Daponte et al. (1997) discuss how to quantify this uncertainty. Given the imperfection of the estimates Bayesian methods that impose some prior knowledge of the structure of the data may lead to improved mortality estimates; this approach is used by Girosi and King (2008).

Given the large role that under-five mortality rates play in determining life expectancy (Vaupel 1986) these examples demonstrate the type of issues that have to be addressed when constructing life expectancy estimates. In developed countries mortality at older ages plays a larger role in variations in life expectancy (White 2002). 
These caveats on data quality mean that we should not draw too much in the way of inference from small differences in estimated life expectancies. The data may however be sufficiently reliable to discern some broad movement in health. Until the advert of HIV/AIDS, infant mortality rates were falling, and life expectancy was rising worldwide, even in countries with little or no growth in income (Ahmad, Lopez, \& Inoue, 2000, Cutler, Deaton and LlerasMuney, 2006). In the following sections we shall investigate to what extent this represents convergence in health and what factors are driving these health gains.

Overall, our analysis points to some possible improvements in the measurement of health as a human development indicator. Conceptually there is a strong argument for using healthy life expectancy, adjusting life expectancy downward for years lived with disability, as our health metric. However this would require a major new data collection effort to collect data on the prevalence of disability. Figure 1 suggests that life expectancy, which depends only on mortality and not morbidity, may in practice capture a large portion the actual variation in population health. We might also consider how to improve our life expectancy measure to adjust for inequality, or risk, due to the variance of life span outcomes. There is scope for improvement in data quality, particularly in developing countries where life expectancy is often modeled based on very sparse data rather than estimated from actual age specific mortality rates.

\section{Improvement and Convergence in Life Expectancy}

The general consensus in the literature is that while income per gaps have been fairly constant over the last 50 years, health status is low health countries has been improving faster than in high health countries leading to a convergence in population health levels around the world (Deaton 
(2004)) . The issue of convergence is important for the human development index since countries are measured relative to the leading country. Uniform improvements with no convergence will mean that average value of the human development index across countries will remain the same. However if there is convergence the average value of the index will rise as countries close with the leader.

In this section we discuss three challenges to this consensus of convergence. First, the picture of convergence depends on which health measure we take, and is sensitive to transformation of the health measure. For example, log life expectancy may not be converging while life expectancy does converge. We show this dependence on functional transformation is fundamental and means we should use conceptually correct measures of health so we are talking about convergence of interesting and meaningful variables. Secondly, we show that the picture of convergence holds from 1970 to 1985 but since 1990 there has been large scale divergence. Thirdly, if we measure population health in terms of life expectancy we show that the picture is of two convergence clubs rather than uniform convergence over the period 1970-2005. All countries that had good levels of health in 1970, and some countries that had low levels, are converging towards a common high level of life expectancy. However there is a substantial group of countries, whose health status was low in 1970, that are converging together towards a much lower level of life expectancy.

Health, as measured by life expectancy, has been improving in most countries over the last fifty years. In addition to this evidence of improvement on average, there is evidence that life expectancy is rising fastest in countries that had low life expectancy in 1970, leading to the view that life expectancy gaps between countries are narrowing, with the prospect of convergence in 
health in the long run (Deaton, 2004; Neumayer, 2003; Sab and Smith, 2002; Hobijn and Franses 2001).

One way to think about convergence in life expectancy is to ask if countries with lower initial life expectancy tend to see larger gains in life expectancy. In this case a regression of the change in life expectancy on the initial level of life expectancy will produce a negative coefficient $\beta$ on life expectancy. Countries with initially low life expectancy will tend to have larger increases in life expectancy (this is known as $\beta$ - convergence). That is we estimate the model

$$
\Delta L_{i}=\alpha+\beta L_{i}+\varepsilon_{i}
$$

where $\Delta L_{i}$ is the change in life expectancy and $L_{i}$ is initial life expectancy. Figure 2 shows the relationship between life expectancy in 1950 and subsequent gains in life expectancy over the period 1950 to $2005^{1}$. The data we use in this section is from United Nations World Population Prospects (2010) and gives life expectancy for 197 countries over the period 1950-2005. An alternative approach to thinking about convergence based on declines over time in the standard deviation of life expectancy across countries known as $\sigma$ - convergence is discussed in the web appendix.

We estimate equation (1) and report the results as model 1 in Table 1 . Both Figure 2 and Table 1 suggest that there is $\beta$-convergence, the trend line in Figure 2 is downward sloping, and the estimate of $\beta$, the coefficient on initial health in 1970 , is negative and statistically significant.

${ }^{1}$ Life expectancy is calculated form mortality rates over a period. Life expectancy 1950 is based on mortality rates over the period 1950-1955 while life expectancy 2005 is based on mortality rates over 2005-2010. 
A difficulty with the concept of $\beta$-convergence is that it is not invariant to transformations of the data. To show this suppose we have

$$
\Delta\left(\log L_{i}\right)=\log (1+\beta)
$$

In this case $\log$ life expectancy is changing at a constant rate $1+\beta$ in each county and is not converging since the rate of change is independent of the initial level of log life expectancy. Transforming this equation we can however derive

$$
\Delta L_{i}=\beta L_{i}
$$

This implies we may have no convergence in log life expectancy but rapid convergence in the level of life expectancy ${ }^{2}$. This issue is fundamental; convergence in the level of a variable does not imply that every positive transform of that variable is also converging. The only solution is to make sure that the health measure we use is the one we are interested in from a welfare perspective.

Even if we accept the evidence of improving and converging life expectancy over the whole period 1950-2005 shown in Figure 2 there is a worry that these average trends mask considerable variation in the experience of individual countries. McMichael, McKee, Shkolnikov and Valkonen (2004) divide countries into three groups, those that have seen rapid improvement in life expectancy over the period, those that have seen relative stagnation in their life expectancy, and those that have seen sharp reversals and falling lifespan in recent years. Molina and Purser

${ }^{2}$ An extreme version of this occurs with infant mortality rates. These are converging towards zero in most countries but the log infant mortality rates are not converging and may remain widely separated. 
(2010) show that life expectancy is converging worldwide, but that this convergence is much more evident if African countries are excluded from the sample.

We argue that while, on average, countries with low life expectancy in the 1960's have seen the faster increases, the data tells a more complex story. Figure 3 plots the distribution of life expectancy in 1950, 1975 and 2005, using a kernel density estimator ${ }^{3}$. An examination of the distribution of life expectancy in 1950 reveals twin peaks; there are a group of countries clustered around a life expectancy of about 40 with anther group clustered around a life expectancy of about 60 . By 2005 the modes of both these clusters have moved up to around 50 and 80 respectively. While progress in both groups has been similar, a number of countries appear to have made the jump for the high mortality cluster to the low mortality cluster. The height of the high life expectancy cluster has increased while the density at the low cluster has fallen. Rather than a process of continuous convergence, the data suggest continuous advances within clusters, but with large advances in life expectancy in particular countries due to jumping between clusters.

The twin peaks in the distribution of health may represent a "mortality trap" that parallels the poverty trap that we see in the world income distribution. In this view there are multiple equilibria. There is a trap, with low income and high mortality, but countries can escape from this trap and converge on the high level equilibrium with high income and low mortality. An alternative view is that there is a unique equilibrium for each country which depends on that country's characteristics. This means some countries have characteristics that lock them into low mortality and high income while others have characteristics that give them high mortality and

\footnotetext{
${ }^{3}$ This is, essentially, a smoothed histogram.
} 
low income while by chance there are few countries with characteristics that give outcomes in between these extremes. Bloom, Canning, and Sevilla (2003) test a model where the twin peaks in the income distribution is due to multiple equilibria against a model where different countries have different outcomes based on their characteristics, such as geography and climate. They find that the evidence favors multiple equilibria; countries with very similar characteristics can have very different outcomes.

We now test formally a model of two convergence clubs, allowing for jumps between clubs, against a model where all countries are converging following the same continuous (though nonlinear) rule. Our first model is the simple linear form we have already discussed

Model 1: $\quad \Delta L_{i}=\alpha+\beta L_{i}+\varepsilon_{i} \quad$ where $\varepsilon_{i}$ is distributed $N\left(0, \sigma^{2}\right)$

We take $L_{i}$ to be initial life expectancy in 1970 and $\Delta L_{i}$ to be the change in life expectancy over 1970-2005. A negative coefficient on initial life expectancy implies $\beta$-convergence.

While this model is standard in the literature it is not clear that it fits the data very well. In particular, looking at Figure 2 we see that the largest gains in life expectancy did not occur in the countries that initially had the lowest life expectancy. Rather countries near the middle of the initial distribution of life expectancy seem to have done best. In addition, the appears to be much more variance in the performance of countries that initially had low life expectancy while the health gains we see in countries that had high initial life expectancy are much more tightly grouped. 
Consider again Figure 3 showing the distribution of life expectancy across countries in 1950, 1975 and again in 2005 using a kernel estimator. The striking feature of these plots is the twin peaks in the distribution of life expectancy. Some countries are clustered around a low level of life expectancy while others cluster around a high level of life expectancy, with very few countries being in the middle between these two clusters. Over time, the modal life expectancy in each cluster has moved to the right. However, in addition, some countries appear to have "jumped" from the low life expectancy cluster, reducing its height, to the high life expectancy cluster, increasing the size of its peak.

Figure 3 suggests a more complex model of the evolution of life expectancy is required. We propose a two regime model. In each regime there is convergence to a steady state, but these steady states differ, being higher in regime 1 (the "good" regime) than in regime 2 (the "mortality trap"). Countries are more likely to be the mortality trap regime if their initial life expectancy is low, but there have a chance of "jumping" to the good regime, with a probability that depends on their initial income level.

Formally the model is:

Model 2:

$$
\begin{gathered}
\Delta L_{i}=\alpha_{1}+\beta_{1} L_{i}+\varepsilon_{1 i} \quad \text { where } \varepsilon_{1 i} \text { is distributed } N\left(0, \sigma_{1}^{2}\right) \text { with probability } 1-p_{i} \\
\Delta L_{i}=\alpha_{2}+\beta_{2} L_{i}+\varepsilon_{2 i} \quad \text { where } \varepsilon_{2 i} \text { is distributed } N\left(0, \sigma_{2}^{2}\right) \quad \text { with probability } p_{i} \\
\text { and } p_{i}=\operatorname{CumNorm}\left(p_{0}+p_{1} L_{i}\right)
\end{gathered}
$$


We assume that in each regime there is a linear relationship between initial life expectancy and the improvement in life expectancy. This will generate $\beta$-convergence within each regime. The probability of being in a particular regime depends on initial life expectancy (we assume the likelihood is a linear function of initial life expectancy, translated to a probability by the cumulative normal distribution).

We estimate model 2 by maximum likelihood. Estimation and hypothesis testing using model 2 is not straight forward since the model does not satisfy the usual regularity conditions used in statistical modeling. Our estimation methods require a grid search over possible parameter values, while hypothesis testing requires Monte Carlo methods to estimate the distribution of test statistics. The statistical problems of these types of models, and methods we can use to overcome them, are described in detail in Bloom, Canning and Sevilla (2003).

The results of our estimation are shown in columns 2 and 3 of table 1 . We estimate two regimes each with $\beta$-convergence, but with different slopes. The "mortality trap" regime gives smaller improvements in life expectancy at each level of live expectancy. Figure 4 plots the two regimes. The results in table 1 show that the probability of being in the "mortality trap" regime decease as initial life expectancy rises. Countries with life expectancy above 55 in 1970 are almost certain to be in "good" regime. However, for countries with life expectancy below 55 in 1970 there is a probability of being in the good and a probability of remaining in the poverty trap. A likelihood ratio test (based on bootstrapped critical values) of the two regime model against a single regime decisively rejects a single regime; the two regimes fit the date better. The two regime model also fits better than a more complex single regime models that allows for a nonlinear relationship and heteroskedasticity. 
We find that the data rejects the model in which all countries follow the same process in favor of the convergence club approach. In the web appendix we examine the predictions of our model against the actual experience of each country in the data set. A number of countries stand out as exceptional. Among these are a group of countries from Sub-Saharan Africa which had quite large predicted gains in life expectancy but actually saw life expectancy decline. Our model does not predict the large declines in life expectancy in these countries due to HIV/AIDS. The Soviet Union also performed very poorly relative to our prediction, though in this case the causes are related to the collapse of employment, stress, and alcoholism (Shkolnikov et al. 2001).

Our data includes a number of countries that have seen substantial declines in life expectancy since 1990 due to HIV/AIDS. However, as pointed out above our model does not predict these declines and our conclusion that there are two regimes in the data does not depend on the presence of HIV/AIDS. The United Nations World Population Prospects 2004 provides estimates of what life expectancy would have been for each country in the absence of HIV/AIDS. Bloom and Canning 2007 obtain similar results to those shown here using this data that excludes the effect of HIV/AIDS mortality. However the corrections for HIV/AIDS mortality are problematic since they depend on estimates of HIV prevalence and models of progression to AIDS and AIDS mortality rather than data on death by cause. HIV prevalence estimates may be biased downwards by differentially high rates of refusal to undertake a HIV test in surveys by those who suspect they are HIV positive (Bärnighausen et al. 2011).This means that we are unsure how much of the twin regime result is due to HIV/AIDS.

The twin peaks in the distribution of life expectancy in Figure 3 are very similar to the twin peaks in income reported in Quah (1996). This raises the idea that development is not a 
smooth process but involves a trap with low income and poor health. Some countries, however, manage to escape this trap and once they have broken free they converge quickly to the high level equilibrium. This means that we see some countries clustered around the low level trap, while others are clustered around the high level equilibrium, with only a few countries in transition between the two "clubs".

\section{Determinants of Health}

There are a number of factors that lead to health improvements. The proximal determinants are factors that affect nutrition and the disease environment, together with preventive and curative medical interventions. Improvements in nutrition strengthen the immune system and reduce susceptibility to disease. Access to clean water and sanitation can reduce the transmission of fecal contamination and the spread of infection. Preventive interventions, such as vaccination, can immunize against disease. Medical treatment can cure disease. The epidemiological transition sets out a model where countries transition from a high burden of infectious disease to a greater burden of non-infectious disease, though countries can have a dual burden with noninfectious diseases becoming prevalent while the infectious diseases have not been eliminated.

There is a debate about the relative importance of the different factors that affect health. Fogel (2004) emphasizes the historical effect of improving nutrition while Preston (1975) and Deaton (2006) put more weight technological progress and new health interventions. There is evidence of the on public health measures such as clean water and sanitation in cities (Cutler and Miller, 
2005), as well as a role for medical treatment in modern populations (Cutler and McClellan, 2001). The relative importance of these mechanisms clearly varies in different times and places, and the interaction between them makes a precise accounting difficult.

An alternative to looking at these proximal determinants of health is to look at more distal determinants. We can think of health as being determined my income and education (LlerasMuney, 2005). Income provides the means to purchase nutrition and health inputs and so leads to better health. Although there is a strong case for the direct effect of income on health due to nutrition and health interventions becoming more affordable, it may be that income is also acting as a proxy for a wider measure of socioeconomic status and development and that the causal effect is due to other mechanisms; another possible explanation for the link between income and health at the individual level is that it is relative, and not absolute, income that matters (Lynch et al. 2000, Martikaien et al. 2002, Marmot and Wilkinson 2001, Marmot 2002). A low position in the social hierarchy may induce psychosocial stress that is linked to increased behaviors that put people at risk of ill health and to physiological reactions in the immune system that directly lead to worse health. The relative income hypothesis suggests that inequality has a direct negative effect on health but the evidence for such a direct effect is contested (Deaton, 2002, 2003)

Preston (1975) showed that, across countries, life expectancy was correlated with income per capita, but that the relationship changes over time. In Figure 5 we plot Preston curves for 1970 and 2005. We fit linear relationship between log income per capita and life expectancy in each year. We have put GDP per capita on a log scale to see the relationship more clearly ${ }^{4}$. There is an

\footnotetext{
${ }^{4}$ There are a small number of countries that have very high incomes but relatively low life expectancies that do not seem to fit the usual relationship. These are oil producing countries.
} 
upward slope to the relationship, with life expectancy being higher in countries with higher income per capita. However the relationship changes over time. For a country with a fixed level of income per capita, life expectancy in 2005 will on average be about eight years higher than in 1970. Preston showed that about three quarters of life expectancy increase can be explained by the upward movement of the curve, and about one quarter by countries getting richer and moving along the curve.

The curvature of the relationship between income and health (implicit in our use of log income on the $\mathrm{x}$ axis in Figure 5) suggests that a policy of redistributing income from the rich to the poor will improve average health outcomes since the gains in health of those with low incomes will outweigh the losses of those with high incomes. The World Health Organization's Commission on Social Determinants of Health (2008) argues that in order to improve health inequalities countries and global institutions need to tackle the inequitable distribution of money, power, and resources in the world. The U.K government recently commissioned a report on effective evidence-based strategies for reducing health inequalities in England from 2010. The resulting Marmet Review (2010) advocates a policy of focusing on investment in childhood health and education, and reducing the gradient in living standards through a more progressive tax system. However, this policy prescription depends on the relationship being causal rather than income merely acting as a proxy for some broader notion of socio-economic status, and needs to be balanced against the negative incentive effects of redistributive taxation (Deaton, 2003)

Note that their 1970 GDP per capita is exceptionally high because their oil production is valued at 2005 prices (not 1970 prices). 
The upward slope of the Preston curve gave birth to the idea that increased wealth leads causally to increased health. Pritchett and Summers (1996) argue that focusing on economic growth in developing countries will lead directly to reductions in infant mortality rates and improvements in life expectancy, as they see improved health as a by-product of higher income levels. The problem with this argument is that, as shown by Preston (1995), most of the health gains we have experienced have been due to improvements in health at each level of income, which is likely to be due to technological progress, i.e., using resources more effectively. Bloom and Canning (2001) found that before 1870 health in rich and poor countries was very similar, but after 1870 health improved in rich countries whereas improvements in poor countries only began after 1930. This is consistent with the view that technological advances are employed first in rich countries before eventually diffusing to poorer societies.

Relatively little work has been done that focuses directly on the contribution of technological progress to population health, though Jamison, Sandbu, and Wang (2001) identify technological progress in health and study its determinants while Cutler, Deaton, and Lleras-Muney (2006) conclude that scientific and technical advance is "the ultimate determinant of health". A further argument against focusing on income growth as a method of alleviating health burdens is that although income levels and population health are closely linked, the connection between periods of economic growth and periods of improvement in population health is very weak, suggesting that if the relationship is causal it has long and variable lags (Easterly, 1999) Although rising incomes mean that society has greater resources, these resources are not always applied to health.

Preston's diagram has been taken by many to imply a causal link from wealth to health. In the years since the paper was written, however, the possibility that the link could also run in 
the reverse direction, from improved health to higher incomes, has been investigated. Healthier workers are more productive, and longer life spans create incentives to invest in schooling and save for retirement (Bloom and Canning, 2000). In addition, of course, healthier children are likely to attend school more regularly, absorb more knowledge while in school, and increase their cognitive ability. The health-to-wealth idea has important policy implications because it suggests that health is a cause as well as a consequence of income growth, and can be a powerful instrument of economic development and poverty reduction. Micro-level studies such as those reported by Strauss and Thomas (1998) and Schultz (2005) support this thesis, although work to estimate the size of the effect of health on wealth at the aggregate level is still ongoing (Commission on Macroeconomics and Health, 2001, Bloom Canning and Sevilla, 2004, Acemoglu and Johnson, 2007). 


\section{References}

Acemoglou, D. and Johnson, S. (2007) Disease and development: The effect of life expectancy on economic growth. Journal of Political Economy, 115(6), pp. 925-985.

Ahmad, O.B., Lopez, A.D. and Inoue, M. (2000) The decline in child mortality: a reappraisal, Bulletin of the World Health Organization, 78(10), pp.1175-1191.

Bärnighausen, T., Bor, J., Wandira-Kazibwe, S. and Canning, D. (2011) Correcting HIV prevalence estimates for survey non-participation: an application of Heckman-type selection models to the Zambian Demographic and Health Survey. Epidemiology, 22(1), pp. 27-35.

Becker, G. S., Philipson, T. J. and Soares, R. R. (2005) The quantity and quality of life and the evolution of world inequality. American Economic Review, 95(1), pp. 277-291.

Bloom, D.E. and Canning, D. (2007) Mortality traps and the dynamics of health transitions. Proceedings of the National Academy of Sciences of the United States of America, 104(41), pp.16044-16049.

Bloom, D.E. and Canning D. (2001) Cumulative causality, economic growth and the demographic transition, in Population Matters: Demographic Change, Economic Growth, and Poverty in the Developing World, N. Birdsall, A.C. Kelley, and S.W. Sinding eds., Oxford University Press, New York, pp. 165-197.

Bloom, D.E. and Canning, D. (2000) The health and wealth of nations. Science, 287, pp. 12071208.

Bloom, D.E., Canning, D. and Sevilla, J. (2003), Geography and poverty traps. Journal of Economic Growth, 8(4), pp. 355-378. 
Bloom D.E, Canning, D. and Sevilla, J. (2004) The effect of health on economic growth: A production function approach. World Development, 32(1), pp.1-13.

Bos, E., Vu, M.T., Stephens, P.W. and Patience, W. (1992) Sources of World Bank estimates of current mortality rates. Policy Research Working Paper Series No. 851. World Bank, Washington, D.C..

Commission on the Measurement of Economic Performance and Social Progress (2009), Report of the Commission on the Measurement of Economic Performance and Social Progress, www.stiglitz-sen-fitoussi.fr/en/index.htm.

Commission on Macroeconomics and Health (2001) Macroeconomics and Health: Investing in Health for Economic Development, Geneva, World Health Organization.

Commission on Social Determinants of Health, Closing the gap in a generation: health equity through action on the social determinants of health: final report of the commission on social determinants of health, 2008, Geneva, World Health Organization.

Commission on International Development (1969), Partners in development: report, Praeger.

Cutler, D.M. and Miller, G. (2005) The role of public health improvements in health advances: the twentieth-century United States, Demography, 42(1), pp. 1-22.

Cutler, D.M. and McClellan, M. (2001) Productivity change in health care, American Economic Review, 91(2), pp. 281-286.

Cutler, D., Deaton, A. and Lleras-Muney, A. (2006) The determinants of mortality, Journal of Economic Perspectives, 20(3), pp.97-120. 
Daponte, B.O., Kadane, J.B. and Wolfson, L.J. (1997) Bayesian demography: projecting the Iraqi Kurdish population, 1977-1990. Journal of the American Statistical Association, 92(440), pp. 1256-1267.

Deaton, A. (2002) Policy implications of the gradient of health and wealth. Health Affairs, 21(2), pp. 13-30.

Deaton, A. (2003) Health, inequality, and economic development, Journal of Economic Literature, 41(1), pp. 113-158.

Deaton, A. (2004) Health in an age of globalization. Brookings Trade Forum 2004, Brookings Institution Press, New York. pp. 83-130.

Deaton A. (2006) The great escape: A review essay on Fogel's the escape from hunger and premature death, 1700-2100. Journal of Economic Literature, 44(1), pp. 106-114.

Deaton, A. (2007), Global patterns of income and health: facts, interpretations, and policies, WIDER Annual Lecture UNU World Institute for Development Economics Research, Helsinki.

Easterly, W. (1999) Life during growth, Journal of Economic Growth, 4(3), pp. 239-76.

Edwards, R.D. (2008) The cost of uncertain life span. NBER Working Paper Series, No. 14093.

Fogel, R.W. (2004) The escape from hunger and premature death, 1700-2100: Europe, America, and the Third World. Cambridge: Cambridge University Press..

Fries, J.F. (2003) Measuring and monitoring success in compressing morbidity, Annals of Internal Medicine, 139(5), pp. 455-459.

Girosi, F. and King, G. (2008) Demographic forecasting, Princeton University Press, Princeton. 
Heston, A., Summers, R. and Aten, B. (2011) Penn World Table Version 7.0, Center for International Comparisons of Production, Income and Prices at the University of Pennsylvania. Available at http://pwt.econ.upenn.edu/.

Hill, K. (2003) Adult mortality in the developing world: what we know and how we know it, Population Division, Department of Economic and Social Affairs, United Nations, New York.

Hobijn, B. and Franses, P.H. (2001) Are living standards converging? Structural Change and Economic Dynamics, 12(2), pp. 171-200.

Jamison, D.T., Sandbu, M. and Wang, J. (2001) Cross-country variation in mortality decline, 1962-87: the role of country specific technical progress, Commission on Macroeconomics and Health, Working Paper WG1, No 4, World Health Organization, Geneva.

Kaplow, L. (2007) Discounting dollars, discounting lives: intergenerational distributive justice and efficiency, The University of Chicago Law Review, 74(1), pp. 79-118.

Lleras-Muney A. (2005) The relationship between education and adult mortality in the United States, Review of Economic Studies, 72(1), pp.189-221.

Lynch, J., Davey Smith, G., Kaplan, G.A. and House, J.S. (2000). Income inequality and mortality: importance to health of individual income, psychosocial environment, or material conditions, British Medical Journal 320(7243), pp. 1200-1204.

Lopez, A.D., Ahmad, O.B., Guillot, M., Ferguson, B.D., Salomon, J.A., Murray, C.J.L. and Hill, K.H. (2003) Life tables for 191 countries for 2000: data, methods, results. In: Murray, C.J.L. and Evans, D.B., eds. Health systems performance assessment: debates, methods and empiricism. Geneva, World Health Organization, pp. 335-353. 
Mathers, C.D., Salomon, J.A., Murray, C.J.L. and Lopez, A.D. (2003) Alternative summary measures of average population health. In: Murray, C.J.L. and Evans D.B. eds. Health systems performance assessment: debates, methods and empiricism. Geneva, World Health Organization, pp. 319-334.

McMichael, A.J., McKee, M., Shkolnikov, V. and Valkonen, T. (2004) Mortality trends and setbacks: global convergence or divergence? Lancet, 363(9415), pp. 1155-1159.

Martikainen, P., Bartley, M., and Lahelma E. (2002) Psychosocial determinants of health in social epidemiology, International Journal of Epidemiology, 31(6), pp. 1091-93.

Marmot, M. and Wilkinson, R.G. (2001) Psychosocial and material pathways in the relation between income and health: a response to Lynch et al. British Medical Journal, 322(7296), pp. $1233-1236$.

Marmot, M. (2002) The influence of income on health: views of an epidemiologist, Health Affairs, 21(2), pp. 31-46.

Marmot, M. (2010), Strategic Review of Health Inequalities in England post-2010, the Marmot Review.

Molina, G.G. and Purser, M. (2010), Human development trends since 1970. United Nations Human Development Program, Human Development Report Working Paper 2010/2, New York.

Neumayer, E. (2003) Beyond income: convergence in living standards, big time. Structural Change and Economic Dynamics, 14(3), pp. 275-96.

Preston, S. (1975) The changing relation between mortality and level of economic development, Population Studies, 29(2), pp. 231-248. 
Pritchett, L. and Summers, L.H. (1996) Wealthier is Healthier. Journal of Human Resources, 31(4), pp. 841-868.

Quah, D.T. (1996) Twin Peaks: Growth and Convergence in Models of Distribution Dynamics, Economic Journal, 106(437), pp.1045-55.

Sab, R. and Smith, S.C. (2002) Human Capital Convergence: A Joint Estimation Approach. IMF Staff Papers, 49(2), pp. 200-211.

Schultz, T.P. (2005) Productive Benefits of Health: Evidence from Low Income Countries, in Health and Economic Growth: Findings and Policy Implications, Lopez-Casasnovas, G., Riveras, B. and Currais L. eds., MIT Press, Cambridge, MA.

Shkolnikov, V., McKee, M. and Leon, D.A. (2001) Changes in life expectancy in Russia in the mid-1990s, Lancet, 357(9260), pp. 917-921.

Strauss, J. and Thomas, D. (1998) Health, Nutrition, and Economic Development, Journal of Economic Literature,; 36(2), pp. 766-817.

United Nations Development Program (1991), Human Development Report 1990, Oxford University Press, New York.

Vaupel, J. W. (1986) How change in age-specific mortality affects life expectancy, Population Studies, 40(1), pp. $147-157$.

Viscusi, W.K. and Aldy, J.E. (2003) The value of a statistical life: a critical review of market estimates from around the world, Journal of Risk and Uncertainty, 27(1), pp. 5-76.

United Nations (2010) World Population Prospects, 2010 Revision. United Nations, New York. 
White, K.M. (2002) Longevity Advances in High-Income Countries, 1955-96. Population and Development Review, 28(1), pp. 59-76.

World Health Organization (2004), World Health Report 2004, World Health Organization, Geneva.

World Bank (2001), World Development Report 2000/2001- Attacking Poverty, World Bank, New York. 
Table 1

\section{Models of Conditional Convergence in Life Expectancy}

Dependent variable, change in life expectancy 1950-2005.

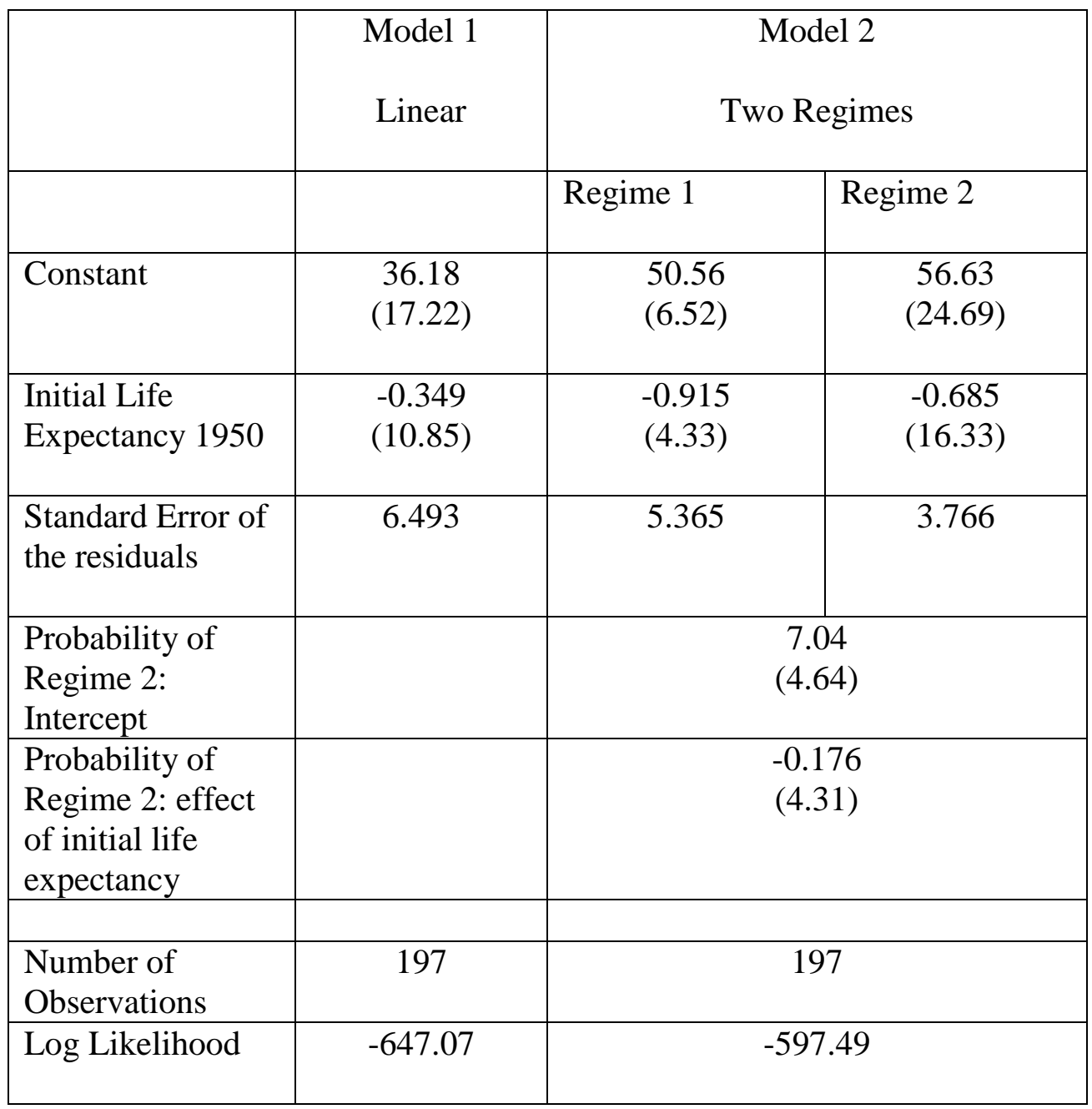

Heteroskedastic consistent $\mathrm{t}$ statistics in parentheses.

Data: United Nations World Population Prospects, 2010 revision. 


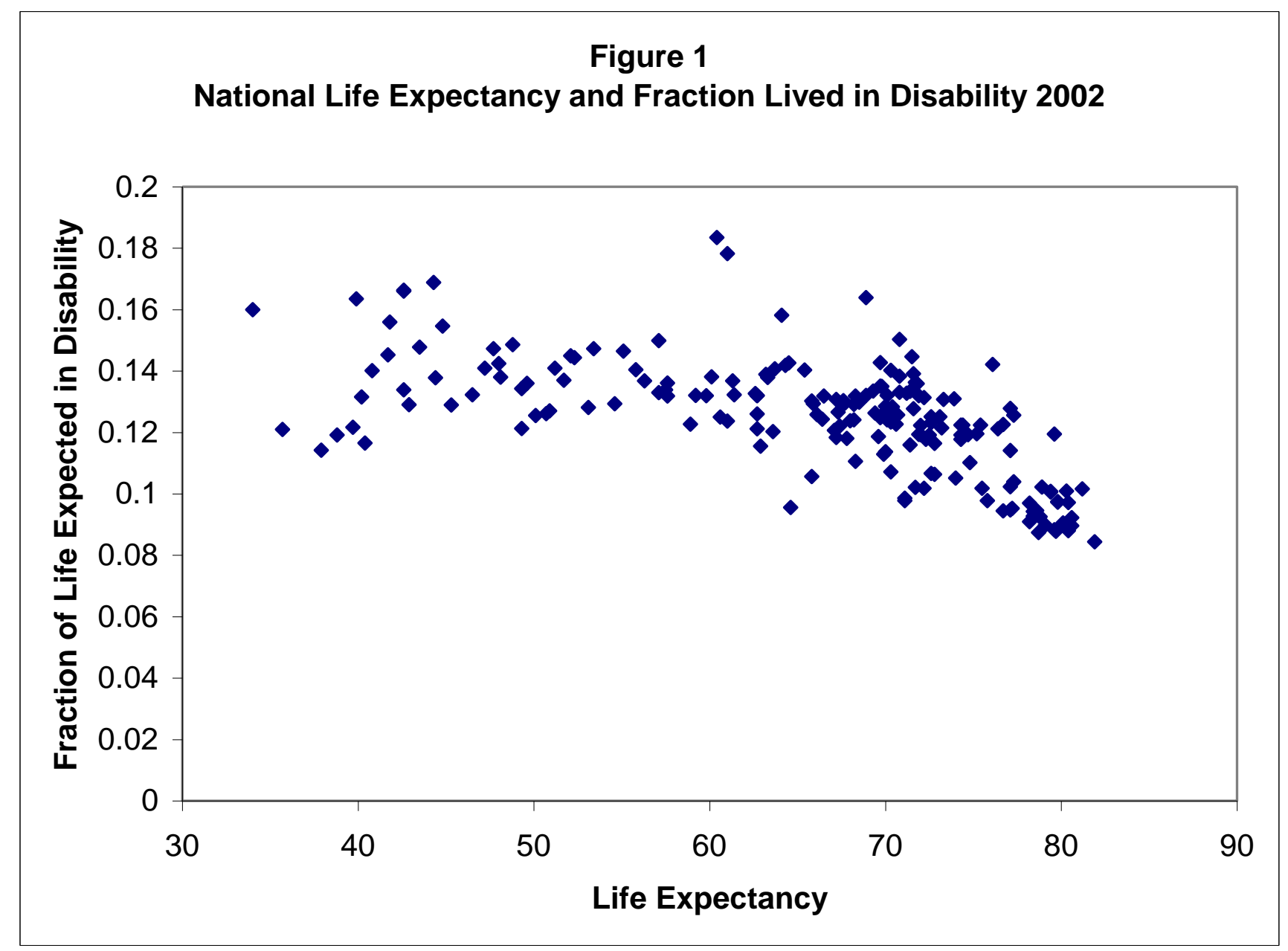

Data: World Health Organization, World Health Report, 2004. 


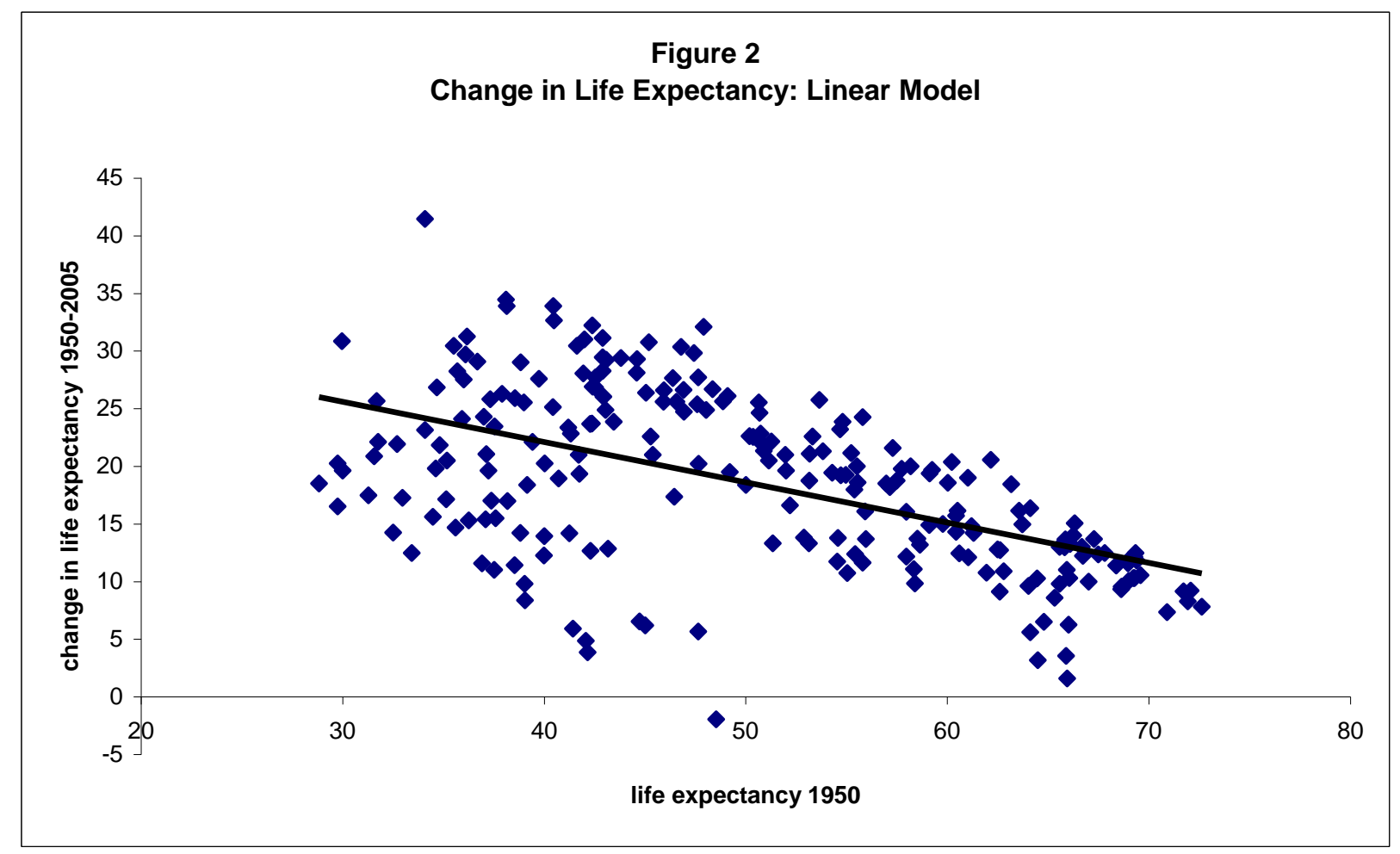

Data: United Nations World Population Prospects, 2010 revision. 


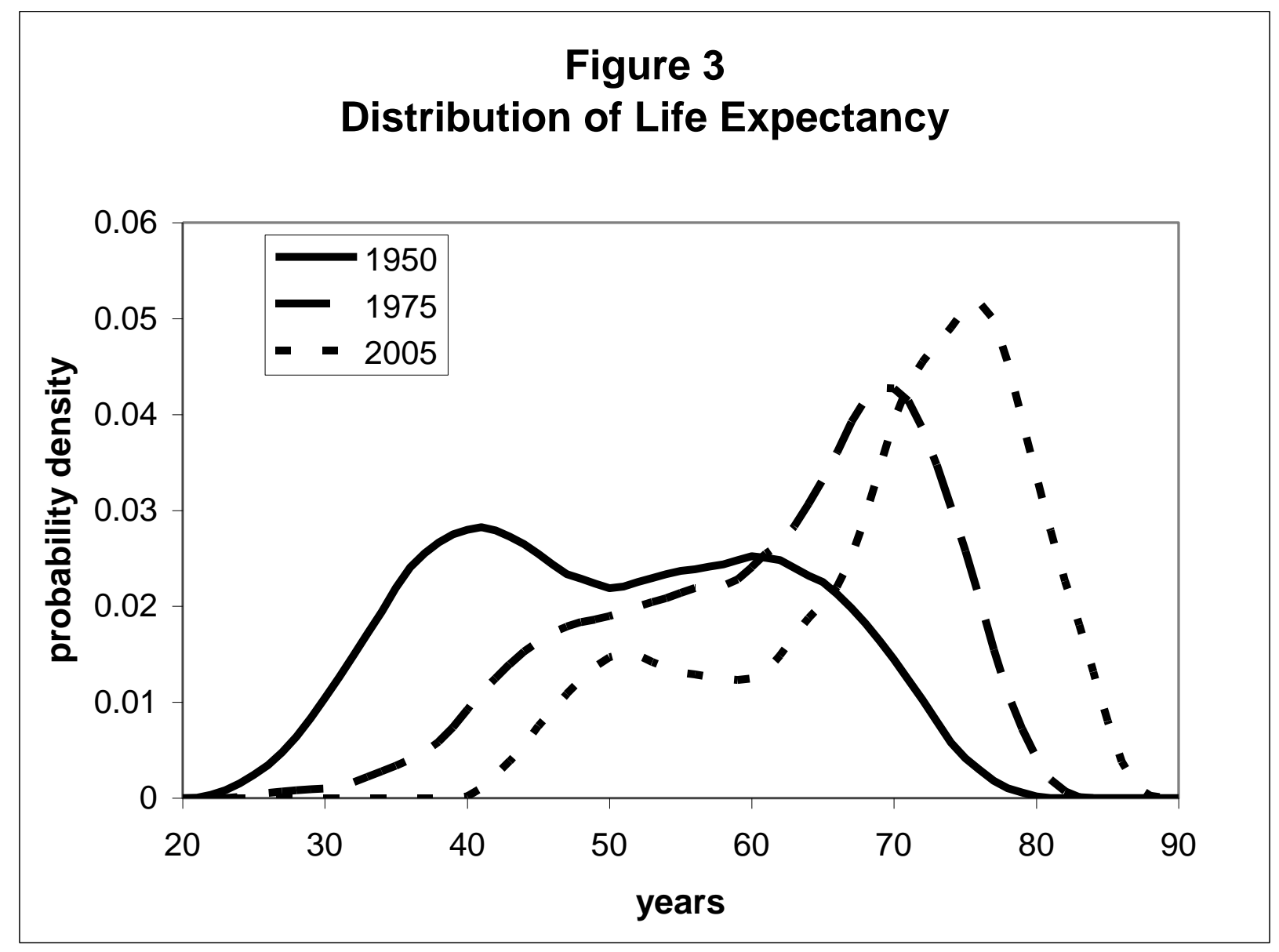

Data: United Nations World Population Prospects, 2010 revision. 


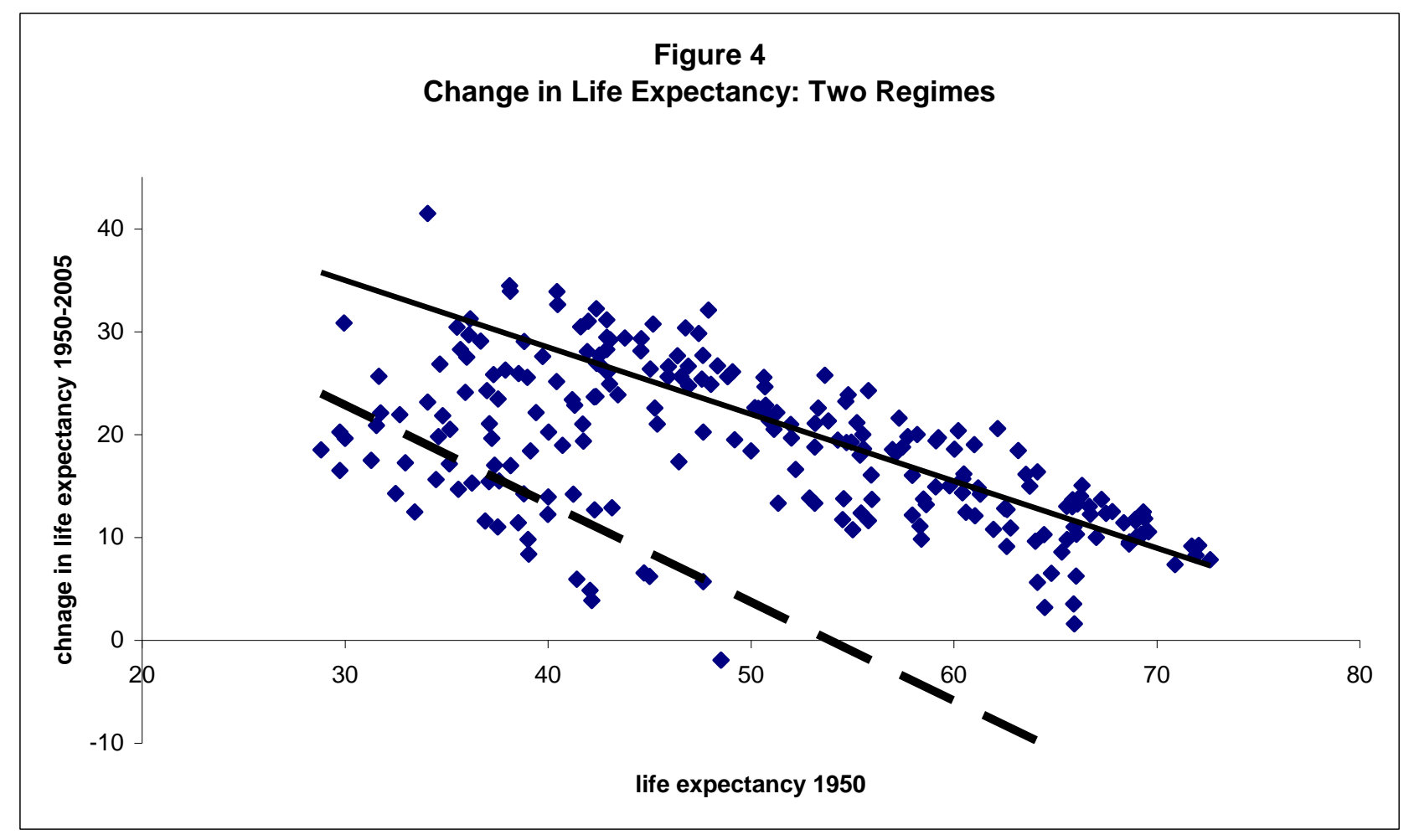

Data: United Nations World Population Prospects, 2010 revision. 


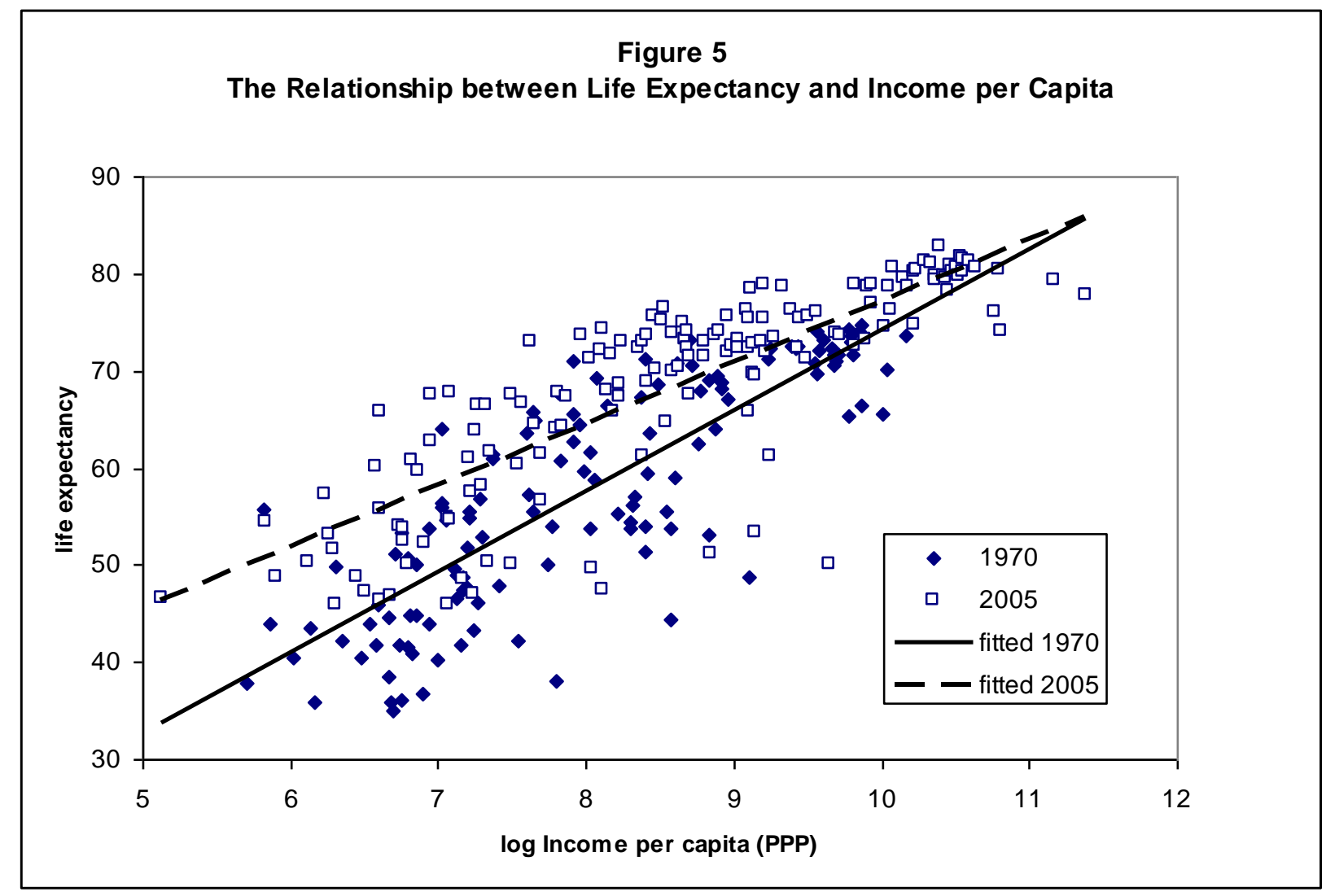

Data: United Nations World Population Prospects, 2010 revision, and Penn World Tables 7.0. 


\section{Appendix}

\section{Life Expectancy and Healthy Life Expectancy}

We can consider different ways of looking at the data on life expectancy and healthy life expectancy in 2002 from the World Health Report 2004. Figure A1 shows a close and almost linear relationship between the two variables. However, in Figure A2 we plot the expected years in disability (life expectancy - healthy life expectancy) against life expectancy. This shows that people living in countries with higher life expectancy expect more years of disability, up to a life expectancy of about 70. For life expectancies above 70 however, increased life expectancy seems to be associated with and lower number of years lived with disability. It appears that at low levels of health, as health improves in terms of longer life spans the onset of disability is also pushed back proportionately, so that the fraction of life spent in disability stays relatively constant.

\section{Under 5 Mortality Estimates for Guatemala and Nigeria}

In Figure A3 we plot under five mortality rates for Guatemala. Guatemala had Demographic and Health Surveys (DHS) in 1987, 1995 and 1998. These surveys tell a fairly consistent story, rates calculated using recall in a later DHS tend to match fairly closely the rates found at the time in an older DHS. In addition Guatemala has a vital registration and figures on under-five mortality from the registered deaths match the DHS estimates quite closely. There are a few very high estimates of under-five mortality in the 1960's but these are not matched by the vital registration data. While the consistency of the data from different sources is encouraging it does not mean that the mortality estimates derived from them are correct; in principle there could be the same bias occurring in each source. 
In Figure A4 we plot estimates of under-five mortality based on data from Demographic and Health Surveys for Nigeria in 1990 and 2003 as well as mortality data from the World Fertility Survey (WFS) in 1981. While the data in figure 1 from different surveys agree quite well over time, the data for Nigeria for under-five mortality based on the three surveys differ markedly. In comparing the data from the 2003 DHS survey in Nigeria with data from the 1990 DHS survey we have the problem that when the data cover the same years they do not overlap. This may be due to recall bias in the later survey, or to one of the surveys not being representative of the overall population. We also have the problem that the recall estimates from the 1990 DHS survey are generally higher than those found at the time in the 1981 World Fertility survey. We are left of the problem of constructing a consistent time series for infant mortality in Nigeria from surveys that give conflicting evidence.

\section{Different Approaches to thinking about Convergence}

In the paper we focused on $\beta$-convergence asking if countries with initial low life expectancy had greater gains over the period, a negative coefficient $\beta$ in equation 1 of the paper. An alternative approach to thinking about convergence is to consider the standard deviation: $\sigma$, of life expectancy across countries and ask whether this measure decreases over time (" $\sigma$ convergence" $)^{5}$. Figure A5 shows the standard deviation of life expectancy for the 174 countries in our sample. The standard deviation of life expectancy across countries fell between 1970 and 1985, but has risen since 1990. This rise is mainly due to the emergence of high HIV/AIDS mortality in countries that already had high mortality which has lead to widening gaps in life

\footnotetext{
${ }^{5} \beta$-convergence is necessary, but not sufficient, for $\sigma$ - convergence. $\beta$-convergence is conditional if we include other variables in the regression. In this case the point to which each country is converging differs and is conditional on these other variables.
} 
expectancy. Figure A6 plots the $10^{\text {th }}, 25^{\text {th }}, 50^{\text {th }}, 75^{\text {th }}$ and $90^{\text {th }}$ percentiles of the life expectancy distribution. Between 1970 and 2005, we can see that there is substantial convergence between the $50^{\text {th }}$ and $90^{\text {th }}$ percentiles. However, since 1990 there has been almost no gains in life expectancy in the $10^{\text {th }}$ to $25^{\text {th }}$ percentiles which is what lies behind the increasing standard deviation in life expectancy across countries.

\section{Convergence, Robustness of the Two Regime Model, and Country Experience}

In table A1 we check for robustness in our results by re-estimating the convergence model reported in Table 1 of the paper using data for the period 1970-2005 from Molina and Purser (2010). The results are quite similar.

The two regime model set out in Table A1 captures the overall picture of movements in life expectancy but some individual countries deviate from the predictions of the model. In Table A2 we list the countries in our dataset in order of their life expectancy in 1970 shown in column 1. In column 2 we show the actual gain in life expectancy in the country over the period 1970-2005. Column 3 shows the expected gain in the country over the period if it is in the "mortality trap" regime. Column 4 shows the expected gain in the high life expectancy regime. Column 5 gives the probability that a country is in the mortality trap regime given its life expectancy in 1970. Column six gives the probability that it is in the mortality trap regime given its 1970 life expectancy and the gain in life expectancy seen over the period 1970-2005. We calculate the posterior probability of the regime given the data using Bayes' rule. We highlight countries in green that appear to have jumped out of the mortality trap over the period, while we highlight in red those who seem to have jumped from the high life expectancy regime into the mortality trap. 
Four countries seem to have jumped out of the mortality trap. Indonesia, Viet Nam, Oman, and Maldives all had low life expectancy in 1970 and based on this the probability we assigned to them being in the mortality trap in column 5 was greater than one half. However, as we can see each of these countries experienced a rapid increase in life expectancy over the period 1970-2005. This rapid gain was in each case much closer to the rapid gain predicted by the high life expectancy regime than the mortality trap. The posterior probability of being in the mortality trap regime given this good performance is in each of the four cases less than one half.

The countries in red, Myanmar, Kenya, Namibia, South Africa, Congo, Botswana and Zimbabwe, all had reasonably high life expectancy in 1970 and we assign them on this basis to being in the high life expectancy regime (their probability of being in the mortality trap in 1970, shown in column 5, is less than one half). However their performance over the period 1970-2005 was poor, indeed South Africa, Congo, Botswana and Zimbabwe all saw decreases in life expectancy. Given this poor performance the posterior probability they are in the mortality trap exceeds one half.

Considering performance relative to that predicted by the initial regime, and looking for jumps between regimes is just one way of thinking about outliers. In Figure A7 we plot actual performance against the expected change in life expectancy for each country. The expected change is the weighed average of the predicted change in each regime from columns 3 and 4 of Table 2; with the weights being the probability of the regime based initial life expectancy as shown in column 5. Figure A7 shows the expected gain declining with initial life expectancy within each regime but rising in the middle of the distribution where the probability of being in the high life expectancy regime is increasing. 
Table A3 lists countries together with their actual and predicted gains in life expectancy as shown in Figure 11. Column 4 in Table A3 gives the actual minus predicted gain and we focus on outliers where this difference is larger than 10 years in absolute magnitude. Countries that jump between regimes shown in table 2 tend to be near the borderline between regimes to begin with. However, outliers in absolute magnitude of their performance come from across the distribution. Bhutan, Western Sahara and Nepal appear to be in mortality trap but had very large gains in life expectancy, though not sufficient to move them out of the trap. On the other hand Indonesia, Viet Nam and Oman are all once again outliers with large gains in life expectancy relative to what we would predict given our model. Swaziland, Zambia, Lesotho, Uganda, Kenya, South Africa, Congo, Botswana and Zimbabwe all had life expectancy gains more than 10 years lower than our model predicts, which can explained by HIV/AIDS. The former Soviet Union also performed very poorly relative to our prediction, though in this case the causes are related to the collapse of employment, stress, and alcoholism (Shkolnikov et al. 2001). 
Table A1

Models of Conditional Convergence in Life Expectancy 1970-2005

Dependent variable, change in life expectancy 1970-2005.

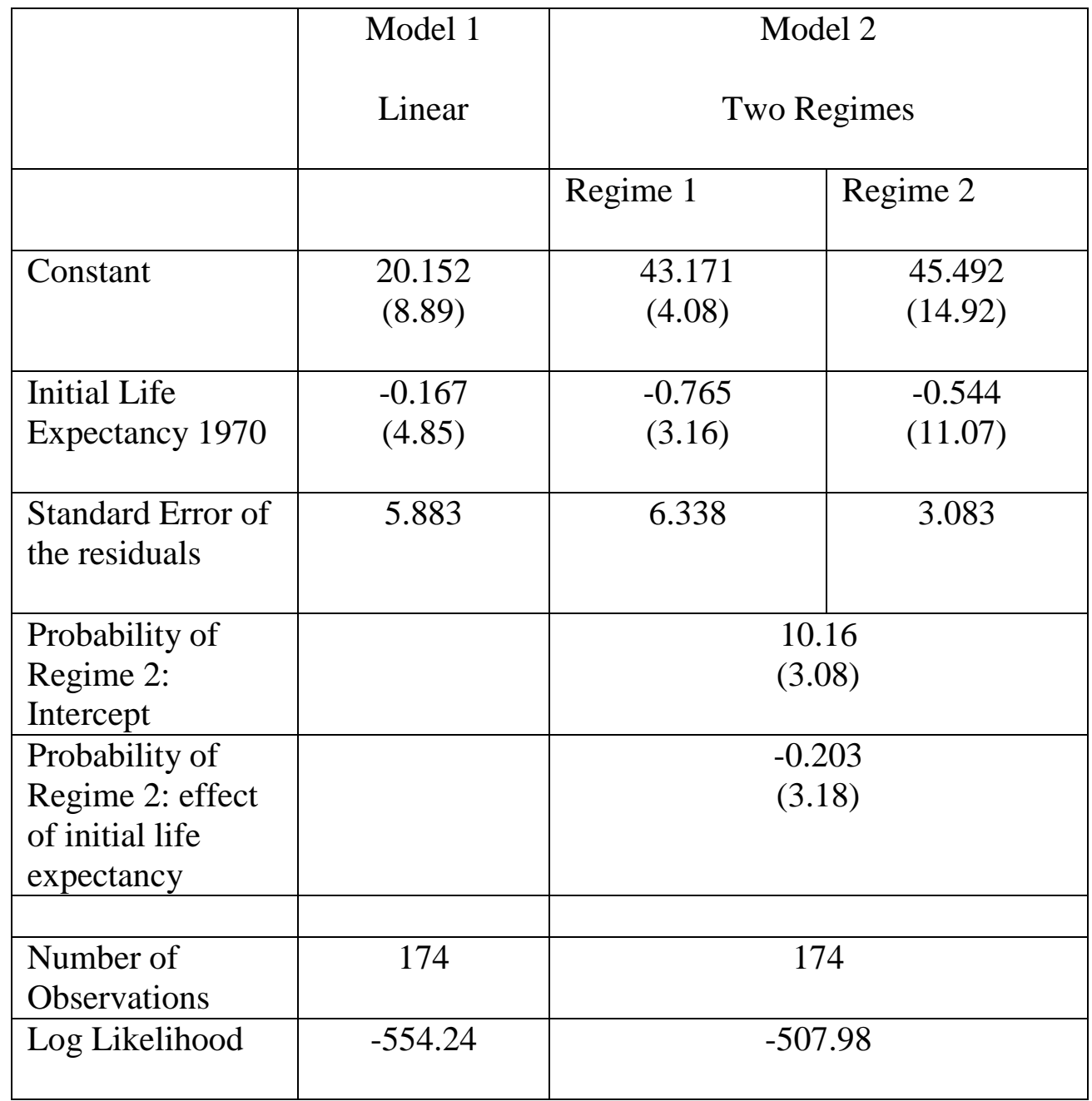

Heteroskedastic consistent $t$ statistics in parentheses

Data Source: Molina and Purser (2010). 
Table A2

Life Expectancy Gains and Regime Predictions 1970-2005

Life Gain in Regime 1 Regime 2 Probability Probability expectancy Life Predicted Predicted of regime 1 regime 1 1970 Expectancy gain gain given 1970 given gain

1970-2005

\begin{tabular}{|c|c|c|c|c|c|c|}
\hline Afghanistan & 35.0 & 7.9 & 16.4 & 26.4 & 1.00 & 1.00 \\
\hline Sierra Leone & 36.0 & 10.4 & 15.7 & 25.9 & 1.00 & 1.00 \\
\hline Angola & 37.0 & 8.5 & 14.9 & 25.4 & 1.00 & 1.00 \\
\hline Guinea-Bissau & 37.2 & 9.8 & 14.7 & 25.3 & 1.00 & 1.00 \\
\hline Mali & 37.5 & 9.8 & 14.5 & 25.1 & 0.99 & 1.00 \\
\hline Niger & 38.1 & 11.5 & 14.0 & 24.7 & 0.99 & 1.00 \\
\hline Yemen & 38.2 & 23.3 & 13.9 & 24.7 & 0.99 & 0.98 \\
\hline Guinea & 39.2 & 17.1 & 13.2 & 24.2 & 0.99 & 1.00 \\
\hline Mozambique & 39.2 & 8.4 & 13.2 & 24.1 & 0.99 & 1.00 \\
\hline Timor-Leste & 39.5 & 20.2 & 12.9 & 24.0 & 0.98 & 0.99 \\
\hline Equatorial Guinea & 39.8 & 9.5 & 12.8 & 23.9 & 0.98 & 1.00 \\
\hline Somalia & 40.1 & 9.5 & 12.5 & 23.7 & 0.98 & 1.00 \\
\hline Nigeria & 40.4 & 6.9 & 12.3 & 23.5 & 0.98 & 1.00 \\
\hline Gambia & 40.6 & 14.6 & 12.1 & 23.4 & 0.97 & 1.00 \\
\hline Malawi & 40.6 & 10.5 & 12.1 & 23.4 & 0.97 & 1.00 \\
\hline Bhutan & 40.6 & 24.2 & 12.1 & 23.4 & 0.97 & 0.86 \\
\hline Burkina Faso & 41.5 & 10.6 & 11.4 & 22.9 & 0.96 & 1.00 \\
\hline \multicolumn{7}{|l|}{ Central African } \\
\hline Republic & 42.0 & 4.2 & 11.1 & 22.7 & 0.95 & 1.00 \\
\hline Western Sahara & 42.0 & 22.9 & 11.0 & 22.6 & 0.95 & 0.77 \\
\hline Senegal & 42.6 & 12.3 & 10.6 & 22.3 & 0.94 & 1.00 \\
\hline Nepal & 42.6 & 22.6 & 10.6 & 22.3 & 0.94 & 0.71 \\
\hline Ethiopia & 42.9 & 10.8 & 10.3 & 22.1 & 0.93 & 1.00 \\
\hline Djibouti & 43.2 & 11.2 & 10.1 & 22.0 & 0.92 & 1.00 \\
\hline Papua New Guinea & 43.3 & 16.7 & 10.1 & 21.9 & 0.92 & 0.96 \\
\hline Eritrea & 43.3 & 15.1 & 10.0 & 21.9 & 0.92 & 0.99 \\
\hline Cambodia & 43.6 & 15.8 & 9.8 & 21.8 & 0.91 & 0.98 \\
\hline Burundi & 43.8 & 5.4 & 9.7 & 21.7 & 0.90 & 1.00 \\
\hline Congo (DR) & 43.8 & 3.8 & 9.6 & 21.6 & 0.90 & 1.00 \\
\hline Madagascar & 43.8 & 15.1 & 9.6 & 21.6 & 0.90 & 0.98 \\
\hline Bangladesh & 44.0 & 20.6 & 9.5 & 21.5 & 0.89 & 0.65 \\
\hline Rwanda & 44.4 & 4.0 & 9.2 & 21.3 & 0.88 & 1.00 \\
\hline Liberia & 44.4 & 12.6 & 9.2 & 21.3 & 0.88 & 1.00 \\
\hline
\end{tabular}




\begin{tabular}{|c|c|c|c|c|c|c|}
\hline & $\begin{array}{c}\text { Life } \\
\text { expectancy } \\
1970\end{array}$ & $\begin{array}{c}\text { Gain in } \\
\text { Life } \\
\text { Expectancy } \\
\text { 1970-2005 }\end{array}$ & $\begin{array}{l}\text { Regime } 1 \\
\text { Predicted } \\
\text { gain }\end{array}$ & $\begin{array}{c}\text { Regime } 2 \\
\text { Predicted } \\
\text { gain }\end{array}$ & $\begin{array}{l}\text { Probability } \\
\text { of regime } 1 \\
\text { given } 1970 \\
\quad \text { life } \\
\text { expectancy }\end{array}$ & $\begin{array}{l}\text { Probability } \\
\text { regime } 1 \\
\text { given gain } \\
1970-2005\end{array}$ \\
\hline Chad & 44.6 & 3.9 & 9.0 & 21.2 & 0.87 & 1.00 \\
\hline Benin & 45.5 & 14.7 & 8.4 & 20.8 & 0.82 & 0.95 \\
\hline Bolivia & 45.8 & 18.9 & 8.2 & 20.6 & 0.81 & 0.54 \\
\hline Cameroon & 45.9 & 4.7 & 8.0 & 20.5 & 0.80 & 1.00 \\
\hline Lao PDR & 46.0 & 17.6 & 8.0 & 20.4 & 0.80 & 0.66 \\
\hline Sudan & 46.4 & 10.9 & 7.7 & 20.3 & 0.77 & 1.00 \\
\hline Gabon & 46.7 & 12.8 & 7.5 & 20.1 & 0.75 & 1.00 \\
\hline Tanzania & 46.7 & 7.0 & 7.5 & 20.1 & 0.75 & 0.97 \\
\hline Côte d'Ivoire & 47.0 & 9.0 & 7.2 & 19.9 & 0.73 & 1.00 \\
\hline Haiti & 47.2 & 13.2 & 7.1 & 19.8 & 0.72 & 0.94 \\
\hline Indonesia & 47.6 & 22.1 & 6.8 & 19.6 & 0.69 & 0.14 \\
\hline Mauritania & 47.7 & 8.8 & 6.7 & 19.6 & 0.69 & 1.00 \\
\hline Comoros & 47.7 & 16.4 & 6.7 & 19.5 & 0.69 & 0.54 \\
\hline Swaziland & 48.0 & -3.0 & 6.4 & 19.4 & 0.66 & 1.00 \\
\hline India & 48.8 & 13.9 & 5.8 & 18.9 & 0.60 & 0.73 \\
\hline Viet Nam & 48.8 & 25.0 & 5.8 & 18.9 & 0.60 & 0.10 \\
\hline Ghana & 48.9 & 7.7 & 5.8 & 18.9 & 0.60 & 1.00 \\
\hline Zambia & 49.0 & -6.1 & 5.7 & 18.8 & 0.59 & 1.00 \\
\hline Lesotho & 49.0 & -4.2 & 5.7 & 18.8 & 0.59 & 1.00 \\
\hline Togo & 49.3 & 12.1 & 5.5 & 18.7 & 0.56 & 0.88 \\
\hline Oman & 49.5 & 25.5 & 5.3 & 18.6 & 0.55 & 0.08 \\
\hline Uganda & 49.8 & 0.4 & 5.0 & 18.4 & 0.52 & 1.00 \\
\hline Maldives & 49.9 & 20.1 & 5.0 & 18.4 & 0.52 & 0.07 \\
\hline $\begin{array}{l}\text { Egypt } \\
\text { Libyan Arab }\end{array}$ & 50.5 & 19.1 & 4.6 & 18.0 & 0.47 & 0.06 \\
\hline Jamahiriya & 51.3 & 22.0 & 3.9 & 17.6 & 0.40 & 0.03 \\
\hline Myanmar & 51.5 & 9.1 & 3.8 & 17.5 & 0.39 & 0.95 \\
\hline Morocco & 51.6 & 18.9 & 3.7 & 17.4 & 0.38 & 0.04 \\
\hline Saudi Arabia & 51.8 & 20.4 & 3.5 & 17.3 & 0.36 & 0.03 \\
\hline Guatemala & 52.1 & 17.6 & 3.4 & 17.2 & 0.34 & 0.04 \\
\hline Kenya & 52.2 & 0.3 & 3.3 & 17.1 & 0.33 & 1.00 \\
\hline Honduras & 52.4 & 19.1 & 3.1 & 17.0 & 0.32 & 0.02 \\
\hline Vanuatu & 52.5 & 16.8 & 3.0 & 16.9 & 0.31 & 0.04 \\
\hline Namibia & 52.6 & 6.1 & 3.0 & 16.9 & 0.31 & 0.99 \\
\hline Mongolia & 52.6 & 12.9 & 2.9 & 16.9 & 0.31 & 0.23 \\
\hline
\end{tabular}




\begin{tabular}{|c|c|c|c|c|c|c|}
\hline & $\begin{array}{c}\text { Life } \\
\text { expectancy } \\
1970\end{array}$ & $\begin{array}{c}\text { Gain in } \\
\text { Life } \\
\text { Expectancy } \\
\text { 1970-2005 }\end{array}$ & $\begin{array}{l}\text { Regime } 1 \\
\text { Predicted } \\
\text { gain }\end{array}$ & $\begin{array}{l}\text { Regime } 2 \\
\text { Predicted } \\
\quad \text { gain }\end{array}$ & $\begin{array}{c}\text { Probability } \\
\text { of regime } 1 \\
\text { given } 1970 \\
\text { life } \\
\text { expectancy }\end{array}$ & $\begin{array}{l}\text { Probability } \\
\text { regime } 1 \\
\text { given gain } \\
1970-2005\end{array}$ \\
\hline South Africa & 52.8 & -1.0 & 2.8 & 16.8 & 0.29 & 1.00 \\
\hline Algeria & 52.9 & 18.8 & 2.7 & 16.7 & 0.28 & 0.02 \\
\hline Peru & 53.5 & 19.0 & 2.3 & 16.4 & 0.24 & 0.01 \\
\hline Nicaragua & 53.6 & 18.3 & 2.1 & 16.3 & 0.24 & 0.01 \\
\hline Tunisia & 53.7 & 19.8 & 2.1 & 16.3 & 0.23 & 0.01 \\
\hline Iran (IR) & 53.9 & 16.7 & 1.9 & 16.2 & 0.22 & 0.02 \\
\hline $\begin{array}{l}\text { Jordan } \\
\text { Occupied Palestinian }\end{array}$ & 54.0 & 17.9 & 1.9 & 16.1 & 0.21 & 0.01 \\
\hline Territories & 54.0 & 18.9 & 1.8 & 16.1 & 0.21 & 0.01 \\
\hline Pakistan & 54.2 & 11.3 & 1.7 & 16.0 & 0.20 & 0.21 \\
\hline Solomon Islands & 54.2 & 10.6 & 1.7 & 16.0 & 0.20 & 0.31 \\
\hline Congo & 54.4 & -1.1 & 1.5 & 15.9 & 0.19 & 1.00 \\
\hline Botswana & 54.6 & -3.6 & 1.4 & 15.8 & 0.18 & 1.00 \\
\hline Zimbabwe & 54.9 & -13.2 & 1.2 & 15.6 & 0.16 & 1.00 \\
\hline Samoa & 54.9 & 15.9 & 1.2 & 15.6 & 0.16 & 0.01 \\
\hline Syrian Arab Republic & 55.4 & 18.2 & 0.8 & 15.3 & 0.14 & 0.01 \\
\hline Sao Tome and Principe & 55.5 & 9.4 & 0.7 & 15.3 & 0.14 & 0.28 \\
\hline Turkey & 55.7 & 15.7 & 0.6 & 15.2 & 0.13 & 0.01 \\
\hline Cape Verde & 56.5 & 14.0 & 0.0 & 14.8 & 0.10 & 0.01 \\
\hline El Salvador & 56.6 & 14.2 & -0.1 & 14.7 & 0.09 & 0.01 \\
\hline Philippines & 57.2 & 13.8 & -0.6 & 14.4 & 0.07 & 0.01 \\
\hline Ecuador & 57.8 & 16.9 & -1.0 & 14.1 & 0.06 & 0.00 \\
\hline Iraq & 58.0 & 10.5 & -1.2 & 13.9 & 0.05 & 0.02 \\
\hline Dominican Republic & 58.4 & 13.7 & -1.5 & 13.7 & 0.05 & 0.00 \\
\hline Brazil & 58.6 & 13.1 & -1.6 & 13.6 & 0.04 & 0.00 \\
\hline Korea (Republic of) & 59.2 & 19.4 & -2.1 & 13.3 & 0.03 & 0.00 \\
\hline Thailand & 59.4 & 9.0 & -2.3 & 13.2 & 0.03 & 0.02 \\
\hline Fiji & 59.6 & 8.7 & -2.4 & 13.1 & 0.03 & 0.02 \\
\hline Guyana & 59.7 & 5.8 & -2.5 & 13.0 & 0.03 & 0.15 \\
\hline French Polynesia & 60.1 & 13.6 & -2.8 & 12.8 & 0.02 & 0.00 \\
\hline Qatar & 60.5 & 14.5 & -3.1 & 12.6 & 0.02 & 0.00 \\
\hline New Caledonia & 60.5 & 15.2 & -3.1 & 12.6 & 0.02 & 0.00 \\
\hline United Arab Emirates & 60.5 & 16.5 & -3.1 & 12.6 & 0.02 & 0.00 \\
\hline St. Vincent- Grenadines & 60.6 & 10.4 & -3.2 & 12.5 & 0.02 & 0.00 \\
\hline Colombia & 60.9 & 11.4 & -3.4 & 12.4 & 0.01 & 0.00 \\
\hline
\end{tabular}




$\begin{array}{cccccc}\text { Life } & \text { Gain in } & \text { Regime 1 } & \text { Regime 2 } & \text { Probability Probability } \\ \text { expectancy } & \text { Life } & \text { Predicted } & \text { Predicted } & \text { of regime 1 } & \text { regime 1 } \\ 1970 & \begin{array}{c}\text { Expectancy } \\ \text { 1970-2005 }\end{array} & \text { gain } & \text { gain } & \text { given 1970 } & \text { given gain } \\ & & & & \text { life } & 1970-2005 \\ & & & & \text { expectancy }\end{array}$

Malaysia

61.3

12.4

$-3.7$

12.1

0.01

0.00

Mexico

Micronesia

61.4

14.1

$-3.8$

12.1

0.01

0.00

61.6

6.4

$-4.0$

12.0

0.01

0.01

Bahrain

61.7

13.6

$-4.0$

11.9

0.01

0.00

China

62.0

10.6

$-4.2$

11.8

0.01

0.00

Korea (DPR)

62.0

4.8

$-4.2$

11.8

0.01

0.04

Chile

Mauritius

62.0

16.2

$-4.3$

11.8

0.01

0.00

62.2

9.8

11.7

0.01

0.00

Réunion

Sri Lanka

62.4

13.7

11.5

0.01

0.00

62.6

11.1

11.5

0.01

0.00

Suriname

63.3

5.1

$-4.7$

11.0

0.00

0.01

Saint Lucia

63.9

9.2

$-5.3$

64.3

10.6

10.7

0.00

0.00

Grenada

64.7

6.8

$-6.1$

10.5

0.00

0.00

Lebanon

Tonga

Venezuela

65.0

6.5

10.3

0.00

0.00

65.0

10.2

0.00

0.00

French Guiana

65.2

8.3

10.1

0.00

0.00

Panama

65.4

10.3

10.0

0.00

0.00

Paraguay

65.4

9.8

9.9

0.00

0.00

65.6

5.9

9.9

0.00

0.00

Guam

9.5

9.8

0.00

0.00

Trinidad and Tobago

65.6

3.1

$-7.0$

9.8

0.00

0.00

Macao, China (SAR)

65.8

14.2

9.7

0.00

0.00

66.2

6.2

9.5

0.00

0.00

Kuwait

66.4

10.9

9.4

0.00

0.00

66.4

9.0

9.4

0.00

0.00

Argentina

Brunei Darussalam

66.6

8.2

$-7.6$

9.3

0.00

0.00

66.7

10.1

9.2

0.00

0.00

66.7

12.0

9.2

0.00

0.00

66.8

11.6

$-7.9$

9.1

0.00

0.00

67.0

9.2

$-8.0$

9.1

0.00

0.00

67.1

11.1

9.0

0.00

0.00

67.7

10.8

8.7

0.00

0.00

67.9

6.7

8.6

0.00

0.00

67.9

11.3

8.5

0.00

0.00

68.0

4.0

8.5

0.00

0.00 


$\begin{array}{cccccc}\text { Life } & \text { Gain in } & \text { Regime 1 } & \text { Regime 2 } & \text { Probability } & \text { Probability } \\ \text { expectancy } & \text { Life } & \text { Predicted } & \text { Predicted } & \text { of regime 1 } & \text { regime 1 } \\ 1970 & \begin{array}{c}\text { Expectancy } \\ \text { 1970-2005 }\end{array} & \text { gain } & \text { gain } & \text { given 1970 } & \text { given gain } \\ & \text { 1970 } & & \text { life } & 1970-2005 \\ & & & & \text { expectancy }\end{array}$

\begin{tabular}{|c|c|c|c|c|c|c|}
\hline Jamaica & 68.3 & 3.0 & -9.1 & 8.3 & 0.00 & 0.00 \\
\hline Former Soviet Union & 68.5 & -1.9 & -9.2 & 8.2 & 0.00 & 0.01 \\
\hline Barbados & 68.5 & 8.0 & -9.2 & 8.2 & 0.00 & 0.00 \\
\hline Uruguay & 68.7 & 7.0 & -9.4 & 8.1 & 0.00 & 0.00 \\
\hline Singapore & 68.8 & 10.8 & -9.5 & 8.1 & 0.00 & 0.00 \\
\hline Aruba & 69.2 & 5.1 & -9.7 & 7.9 & 0.00 & 0.00 \\
\hline Hungary & 69.3 & 3.6 & -9.9 & 7.8 & 0.00 & 0.00 \\
\hline Netherlands Antilles & 69.4 & 6.4 & -9.9 & 7.8 & 0.00 & 0.00 \\
\hline Cuba & 69.9 & 8.1 & -10.3 & 7.5 & 0.00 & 0.00 \\
\hline Malta & 70.0 & 9.3 & -10.4 & 7.4 & 0.00 & 0.00 \\
\hline Czechoslovakia & 70.1 & 5.3 & -10.4 & 7.4 & 0.00 & 0.00 \\
\hline Finland & 70.1 & 8.9 & -10.5 & 7.4 & 0.00 & 0.00 \\
\hline Austria & 70.1 & 9.3 & -10.5 & 7.3 & 0.00 & 0.00 \\
\hline Luxembourg & 70.2 & 8.7 & -10.5 & 7.3 & 0.00 & 0.00 \\
\hline Poland & 70.2 & 4.9 & -10.6 & 7.3 & 0.00 & 0.00 \\
\hline Cyprus & 70.8 & 8.6 & -11.0 & 7.0 & 0.00 & 0.00 \\
\hline Germany & 70.8 & 8.5 & -11.0 & 7.0 & 0.00 & 0.00 \\
\hline United States & 70.8 & 7.9 & -11.0 & 7.0 & 0.00 & 0.00 \\
\hline Bulgaria & 71.1 & 1.6 & -11.2 & 6.8 & 0.00 & 0.00 \\
\hline $\begin{array}{l}\text { Hong Kong, China } \\
\text { (SAR) }\end{array}$ & 71.1 & 10.9 & -11.2 & 6.8 & 0.00 & 0.00 \\
\hline Belgium & 71.1 & 7.8 & -11.2 & 6.8 & 0.00 & 0.00 \\
\hline Australia & 71.1 & 9.9 & -11.3 & 6.8 & 0.00 & 0.00 \\
\hline Ireland & 71.2 & 7.7 & -11.3 & 6.8 & 0.00 & 0.00 \\
\hline Israel & 71.2 & 9.1 & -11.3 & 6.8 & 0.00 & 0.00 \\
\hline New Zealand & 71.4 & 8.4 & -11.5 & 6.6 & 0.00 & 0.00 \\
\hline Italy & 71.5 & 9.3 & -11.5 & 6.6 & 0.00 & 0.00 \\
\hline Puerto Rico & 71.7 & 6.8 & -11.6 & 6.5 & 0.00 & 0.00 \\
\hline United Kingdom & 71.7 & 7.3 & -11.7 & 6.5 & 0.00 & 0.00 \\
\hline Greece & 71.7 & 7.0 & -11.7 & 6.5 & 0.00 & 0.00 \\
\hline France & 71.8 & 8.6 & -11.8 & 6.4 & 0.00 & 0.00 \\
\hline Japan & 72.2 & 10.2 & -12.1 & 6.2 & 0.00 & 0.00 \\
\hline Spain & 72.2 & 8.1 & -12.1 & 6.2 & 0.00 & 0.00 \\
\hline Canada & 72.5 & 7.7 & -12.3 & 6.0 & 0.00 & 0.00 \\
\hline Switzerland & 72.9 & 8.4 & -12.6 & 5.8 & 0.00 & 0.00 \\
\hline
\end{tabular}




$\begin{array}{cccccc}\begin{array}{c}\text { Life } \\ \text { expectancy } \\ 1970\end{array} & \begin{array}{c}\text { Gain in } \\ \text { Life } \\ \text { Expectancy } \\ 1970-2005\end{array} & \begin{array}{c}\text { Regime 1 } \\ \text { Predicted } \\ \text { gain }\end{array} & \begin{array}{c}\text { Regime 2 } \\ \text { Predicted } \\ \text { gain }\end{array} & \begin{array}{c}\text { Probability } \\ \text { of regime 1 } \\ \text { given 1970 } \\ \text { life }\end{array} & \begin{array}{c}\text { Probability } \\ \text { given gain }\end{array} \\ \text { 1970-2005 } \\ 73.2 & 4.6 & -12.9 & 5.6 & 0.00 & 0.00 \\ 73.7 & 5.6 & -13.2 & 5.4 & 0.00 & 0.00 \\ 73.7 & 7.8 & -13.2 & 5.4 & 0.00 & 0.00 \\ 74.1 & 5.9 & -13.5 & 5.2 & 0.00 & 0.00 \\ 74.4 & 6.1 & -13.8 & 5.0 & 0.00 & 0.00\end{array}$


Table A3

Outliers based on Life Expectancy Gains and Predicted Gain 1970-2005

\begin{tabular}{|c|c|c|c|c|}
\hline & $\begin{array}{c}\text { Life } \\
\text { Expectancy } \\
1970\end{array}$ & $\begin{array}{c}\text { Gain in } \\
\text { Life } \\
\text { Expectancy } \\
1970-2005\end{array}$ & $\begin{array}{l}\text { Predicted } \\
\text { gain: } \\
\text { two regime } \\
\text { model }\end{array}$ & $\begin{array}{l}\text { Actual } \\
\text { minus } \\
\text { Predicted } \\
\text { Gain }\end{array}$ \\
\hline Afghanistan & 35.0 & 7.9 & 16.4 & -8.6 \\
\hline Sierra Leone & 36.0 & 10.4 & 15.7 & -5.3 \\
\hline Angola & 37.0 & 8.5 & 14.9 & -6.4 \\
\hline Guinea-Bissau & 37.2 & 9.8 & 14.7 & -5.0 \\
\hline Mali & 37.5 & 9.8 & 14.6 & -4.7 \\
\hline Niger & 38.1 & 11.5 & 14.1 & -2.5 \\
\hline Yemen & 38.2 & 23.3 & 14.0 & 9.3 \\
\hline Guinea & 39.2 & 17.1 & 13.3 & 3.7 \\
\hline Mozambique & 39.2 & 8.4 & 13.3 & -4.9 \\
\hline Timor-Leste & 39.5 & 20.2 & 13.1 & 7.1 \\
\hline Equatorial Guinea & 39.8 & 9.5 & 13.0 & -3.5 \\
\hline Somalia & 40.1 & 9.5 & 12.7 & -3.2 \\
\hline Nigeria & 40.4 & 6.9 & 12.6 & -5.7 \\
\hline Gambia & 40.6 & 14.6 & 12.4 & 2.2 \\
\hline Malawi & 40.6 & 10.5 & 12.4 & -1.9 \\
\hline Bhutan & 40.6 & 24.2 & 12.4 & 11.8 \\
\hline Burkina Faso & 41.5 & 10.6 & 11.9 & -1.3 \\
\hline Central African Republic & 42.0 & 4.2 & 11.7 & -7.5 \\
\hline Western Sahara & 42.0 & 22.9 & 11.6 & 11.3 \\
\hline Senegal & 42.6 & 12.3 & 11.4 & 1.0 \\
\hline Nepal & 42.6 & 22.6 & 11.4 & 11.3 \\
\hline Ethiopia & 42.9 & 10.8 & 11.2 & -0.3 \\
\hline Djibouti & 43.2 & 11.2 & 11.1 & 0.2 \\
\hline Papua New Guinea & 43.3 & 16.7 & 11.1 & 5.6 \\
\hline Eritrea & 43.3 & 15.1 & 11.0 & 4.1 \\
\hline Cambodia & 43.6 & 15.8 & 10.9 & 4.9 \\
\hline Burundi & 43.8 & 5.4 & 10.9 & -5.5 \\
\hline Congo (Democratic Republic of the) & 43.8 & 3.8 & 10.8 & -7.0 \\
\hline Madagascar & 43.8 & 15.1 & 10.8 & 4.3 \\
\hline Bangladesh & 44.0 & 20.6 & 10.8 & 9.8 \\
\hline Rwanda & 44.4 & 4.0 & 10.7 & -6.7 \\
\hline Liberia & 44.4 & 12.6 & 10.7 & 1.9 \\
\hline Chad & 44.6 & 3.9 & 10.6 & -6.7 \\
\hline Benin & 45.5 & 14.7 & 10.6 & 4.1 \\
\hline Bolivia & 45.8 & 18.9 & 10.6 & 8.3 \\
\hline
\end{tabular}


Cameroon

Lao People's Democratic Republic

Sudan

Gabon

Tanzania (United Republic of)

Côte d'Ivoire

Haiti

Indonesia
Mauritania
Comoros
Swaziland
India
Viet Nam
Ghana
Zambia
Lesotho

Togo

Oman

Uganda

Maldives

Egypt

Libyan Arab Jamahiriya

Myanmar

Morocco

Saudi Arabia

Guatemala

Kenya

Honduras

Vanuatu

Namibia

Mongolia

South Africa

Algeria

Peru

Nicaragua

Tunisia

Iran (Islamic Republic of)

$\begin{array}{cccc}\begin{array}{c}\text { Life } \\ \text { Expectancy } \\ 1970\end{array} & \begin{array}{c}\text { Gain in } \\ \text { Life } \\ \text { Expectancy } \\ 1970-2005\end{array} & \begin{array}{c}\text { Predicted } \\ \text { gain: } \\ \text { two regime } \\ \text { model }\end{array} & \begin{array}{c}\text { Actual } \\ \text { minus } \\ \text { Predicted } \\ \text { Gain }\end{array} \\ 45.9 & 4.7 & 10.5 & -5.8 \\ 46.0 & 17.6 & 10.5 & 7.1 \\ 46.4 & 10.9 & 10.6 & 0.3 \\ 46.7 & 12.8 & 10.6 & 2.2 \\ 46.7 & 7.0 & 10.6 & -3.6 \\ 47.0 & 9.0 & 10.6 & -1.6 \\ 47.2 & 13.2 & 10.6 & 2.6 \\ 47.6 & 22.1 & 10.7 & 11.4 \\ 47.7 & 8.8 & 10.7 & -2.0 \\ 47.7 & 16.4 & 10.7 & 5.6 \\ 48.0 & -3.0 & 10.8 & -13.8 \\ 48.8 & 13.9 & 11.0 & 2.9 \\ 48.8 & 25.0 & 11.0 & 14.0 \\ 48.9 & 7.7 & 11.1 & -3.5 \\ 49.0 & -6.1 & 11.1 & -17.2 \\ 49.0 & -4.2 & 11.1 & -15.3 \\ 49.3 & 12.1 & 11.3 & 0.8 \\ 49.5 & 25.5 & 11.3 & 14.2 \\ 49.8 & 0.4 & 11.4 & -11.0 \\ 49.9 & 20.1 & 11.5 & 8.6 \\ 50.5 & 19.1 & 11.7 & 7.3 \\ 51.3 & 22.0 & 12.1 & 9.9 \\ 51.5 & 9.1 & 12.2 & -3.1 \\ 51.6 & 18.9 & 12.2 & 6.7 \\ 51.8 & 20.4 & 12.3 & 8.1 \\ 52.1 & 17.6 & 12.5 & 5.1 \\ 52.2 & 0.3 & 12.5 & -12.2 \\ 52.4 & 19.1 & 12.6 & 6.5 \\ 52.5 & 16.8 & 12.6 & 4.2 \\ 52.6 & 6.1 & 12.7 & -6.6 \\ 52.6 & 12.9 & 12.6 & 0.3 \\ 52.8 & -1.0 & 12.7 & -13.7 \\ 52.9 & 18.8 & 12.7 & 6.0 \\ 53.5 & 19.0 & 13.0 & 6.0 \\ 53.6 & 18.3 & 12.9 & 5.4 \\ 53.7 & 19.8 & 13.0 & 6.8 \\ 53.9 & 16.7 & 13.1 & 3.7\end{array}$




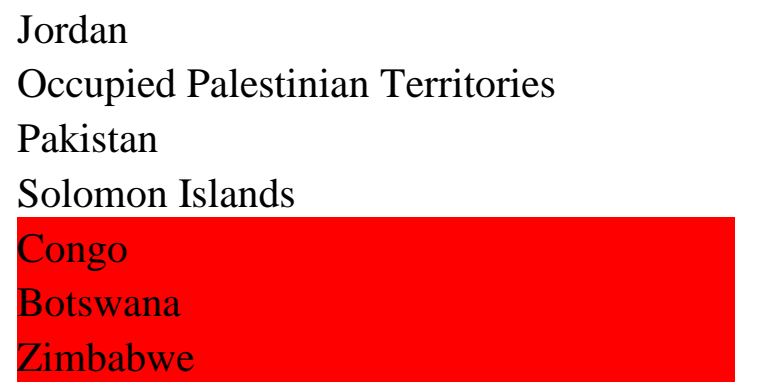

Samoa

Syrian Arab Republic

Sao Tome and Principe

Turkey

Cape Verde

El Salvador

Philippines

Ecuador

Iraq

Dominican Republic

Brazil

Korea (Republic of)

Thailand

Fiji

Guyana

French Polynesia

Qatar

New Caledonia

United Arab Emirates

Saint Vincent and the Grenadines

Colombia

Malaysia

Mexico

Micronesia (Federated States of)

Bahrain

China

Korea (Democratic People's Rep. of)

Chile

Mauritius

Réunion

$\begin{array}{cccc}\text { Life } & \text { Gain in } & \text { Predicted } & \text { Actual } \\ \text { Expectancy } & \text { Life } & \text { gain: } & \text { minus } \\ 1970 & \text { Expectancy } & \text { two regime } & \text { Predicted } \\ & 1970-2005 & \text { model } & \text { Gain }\end{array}$

54.0

54.0

54.2

54.2

54.4

54.6

54.9

54.9

55.4

55.5

55.7

56.5

56.6

57.2

57.8

58.0

58.4

58.6

59.2

59.4

59.6

59.7

60.1

60.5

60.5

60.5

60.6

60.9

61.3

61.4

61.6

61.7

62.0

62.0

62.0

62.2

62.4

\section{9}

18.9

11.3

10.6

$-1.1$

$-3.6$

$-13.2$

15.9

18.2

9.4

15.7

14.0

14.2

13.8

16.9

10.5

13.7

13.1

19.4

9.0

8.7

5.8

13.6

14.5

15.2

16.5

10.4

11.4

12.4

14.1

6.4

13.6

10.6

4.8

16.2

9.8

13.7
13.1

13.0

13.1

13.1

13.2

13.2

13.2

13.2

13.3

13.3

13.3

13.4

13.3

13.3

13.2

13.1

13.0

13.0

12.8

12.7

12.7

12.6

12.5

12.3

12.3

12.3

12.2

12.2

11.9

11.9

11.8

11.8

11.7

11.7

11.7

11.6

11.4 


\begin{tabular}{|c|c|c|c|c|}
\hline & $\begin{array}{c}\text { Life } \\
\text { Expectancy } \\
1970\end{array}$ & $\begin{array}{c}\text { Gain in } \\
\text { Life } \\
\text { Expectancy } \\
\text { 1970-2005 }\end{array}$ & $\begin{array}{l}\text { Predicted } \\
\text { gain: } \\
\text { two regime } \\
\text { model }\end{array}$ & $\begin{array}{c}\text { Actual } \\
\text { minus } \\
\text { Predicted } \\
\text { Gain }\end{array}$ \\
\hline Sri Lanka & 62.6 & 11.1 & 11.4 & -0.3 \\
\hline Suriname & 63.3 & 5.1 & 10.9 & -5.8 \\
\hline Saint Lucia & 63.9 & 9.2 & 10.7 & -1.4 \\
\hline Grenada & 64.3 & 10.6 & 10.5 & 0.1 \\
\hline Lebanon & 64.7 & 6.8 & 10.3 & -3.5 \\
\hline Tonga & 65.0 & 6.5 & 10.2 & -3.7 \\
\hline Venezuela (Bolivarian Republic of) & 65.0 & 8.3 & 10.1 & -1.8 \\
\hline French Guiana & 65.2 & 10.3 & 10.0 & 0.3 \\
\hline Panama & 65.4 & 9.8 & 9.9 & -0.1 \\
\hline Paraguay & 65.4 & 5.9 & 9.9 & -4.0 \\
\hline Guam & 65.6 & 9.5 & 9.8 & -0.3 \\
\hline Trinidad and Tobago & 65.6 & 3.1 & 9.8 & -6.7 \\
\hline Macao, China (SAR) & 65.8 & 14.2 & 9.7 & 4.5 \\
\hline Bahamas & 66.2 & 6.2 & 9.5 & -3.3 \\
\hline Kuwait & 66.4 & 10.9 & 9.4 & 1.5 \\
\hline Belize & 66.4 & 9.0 & 9.4 & -0.4 \\
\hline Argentina & 66.6 & 8.2 & 9.3 & -1.1 \\
\hline Brunei Darussalam & 66.7 & 10.1 & 9.2 & 0.9 \\
\hline Guadeloupe & 66.7 & 12.0 & 9.2 & 2.8 \\
\hline Costa Rica & 66.8 & 11.6 & 9.1 & 2.5 \\
\hline Albania & 67.0 & 9.2 & 9.1 & 0.1 \\
\hline Portugal & 67.1 & 11.1 & 9.0 & 2.1 \\
\hline United States Virgin Islands & 67.7 & 10.8 & 8.7 & 2.1 \\
\hline Yugoslavia & 67.9 & 6.7 & 8.6 & -1.9 \\
\hline Martinique & 67.9 & 11.3 & 8.5 & 2.8 \\
\hline Romania & 68.0 & 4.0 & 8.5 & -4.5 \\
\hline Jamaica & 68.3 & 3.0 & 8.3 & -5.3 \\
\hline Former Soviet Union & 68.5 & -1.9 & 8.2 & -10.0 \\
\hline Barbados & 68.5 & 8.0 & 8.2 & -0.2 \\
\hline Uruguay & 68.7 & 7.0 & 8.1 & -1.1 \\
\hline Singapore & 68.8 & 10.8 & 8.1 & 2.7 \\
\hline Aruba & 69.2 & 5.1 & 7.9 & -2.8 \\
\hline Hungary & 69.3 & 3.6 & 7.8 & -4.2 \\
\hline Netherlands Antilles & 69.4 & 6.4 & 7.8 & -1.4 \\
\hline Cuba & 69.9 & 8.1 & 7.5 & 0.6 \\
\hline Malta & 70.0 & 9.3 & 7.4 & 1.9 \\
\hline Czechoslovakia & 70.1 & 5.3 & 7.4 & -2.1 \\
\hline
\end{tabular}




Finland
Austria
Luxembourg
Poland
Cyprus
Germany
United States
Bulgaria
Hong Kong, China (SAR)
Belgium
Australia
Ireland
Israel
New Zealand
Italy
Puerto Rico
United Kingdom
Greece
France
Japan
Spain
Canada
Switzerland
Denmark
Netherlands
Iceland
Norway
Sweden

\begin{tabular}{|c|c|c|c|}
\hline $\begin{array}{c}\text { Life } \\
\text { Expectancy } \\
1970\end{array}$ & $\begin{array}{c}\text { Gain in } \\
\text { Life } \\
\text { Expectancy } \\
\text { 1970-2005 }\end{array}$ & $\begin{array}{l}\text { Predicted } \\
\text { gain: } \\
\text { two regime } \\
\text { model }\end{array}$ & $\begin{array}{c}\text { Actual } \\
\text { minus } \\
\text { Predicted } \\
\text { Gain }\end{array}$ \\
\hline 70.1 & 8.9 & 7.4 & 1.5 \\
\hline 70.1 & 9.3 & 7.3 & 2.0 \\
\hline 70.2 & 8.7 & 7.3 & 1.4 \\
\hline 70.2 & 4.9 & 7.3 & -2.4 \\
\hline 70.8 & 8.6 & 7.0 & 1.6 \\
\hline 70.8 & 8.5 & 7.0 & 1.5 \\
\hline 70.8 & 7.9 & 7.0 & 0.9 \\
\hline 71.1 & 1.6 & 6.8 & -5.2 \\
\hline 71.1 & 10.9 & 6.8 & 4.1 \\
\hline 71.1 & 7.8 & 6.8 & 1.0 \\
\hline 71.1 & 9.9 & 6.8 & 3.1 \\
\hline 71.2 & 7.7 & 6.8 & 0.9 \\
\hline 71.2 & 9.1 & 6.8 & 2.3 \\
\hline 71.4 & 8.4 & 6.6 & 1.8 \\
\hline 71.5 & 9.3 & 6.6 & 2.7 \\
\hline 71.7 & 6.8 & 6.5 & 0.3 \\
\hline 71.7 & 7.3 & 6.5 & 0.8 \\
\hline 71.7 & 7.0 & 6.5 & 0.5 \\
\hline 71.8 & 8.6 & 6.4 & 2.2 \\
\hline 72.2 & 10.2 & 6.2 & 4.0 \\
\hline 72.2 & 8.1 & 6.2 & 1.9 \\
\hline 72.5 & 7.7 & 6.0 & 1.7 \\
\hline 72.9 & 8.4 & 5.8 & 2.6 \\
\hline 73.2 & 4.6 & 5.6 & -1.0 \\
\hline 73.7 & 5.6 & 5.4 & 0.2 \\
\hline 73.7 & 7.8 & 5.4 & 2.4 \\
\hline 74.1 & 5.9 & 5.2 & 0.7 \\
\hline 74.4 & 6.1 & 5.0 & 1.1 \\
\hline
\end{tabular}




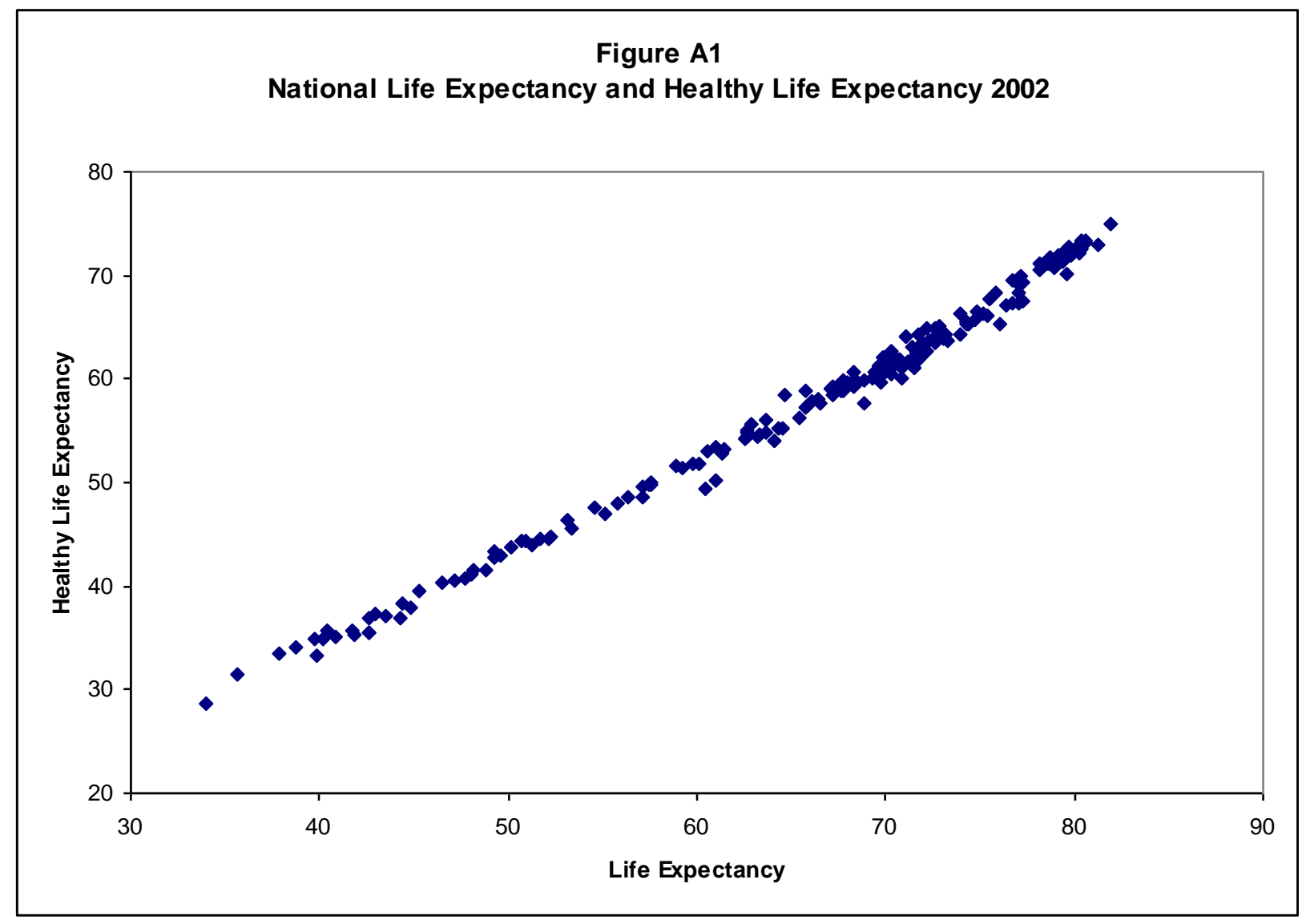

55 


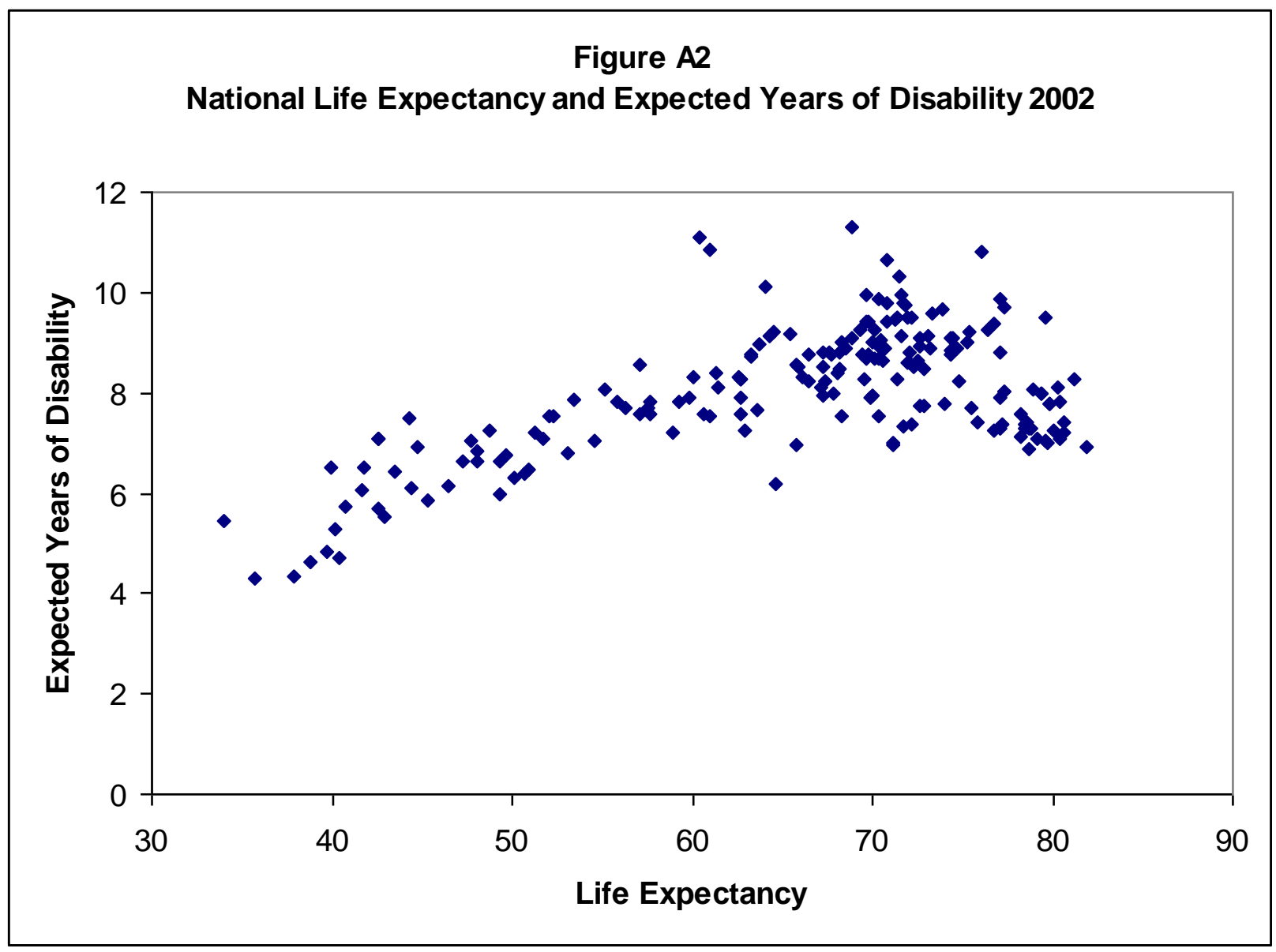




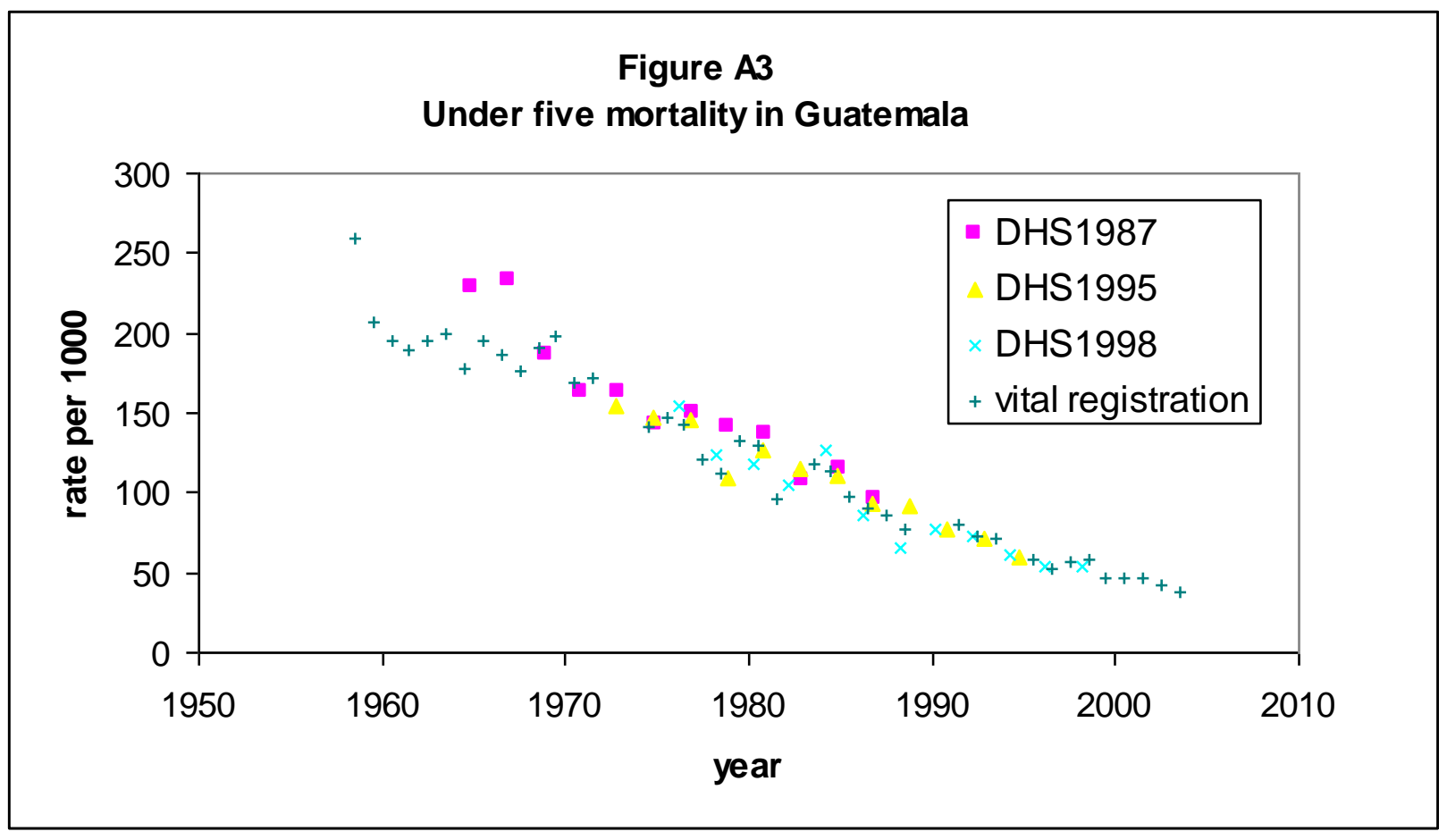




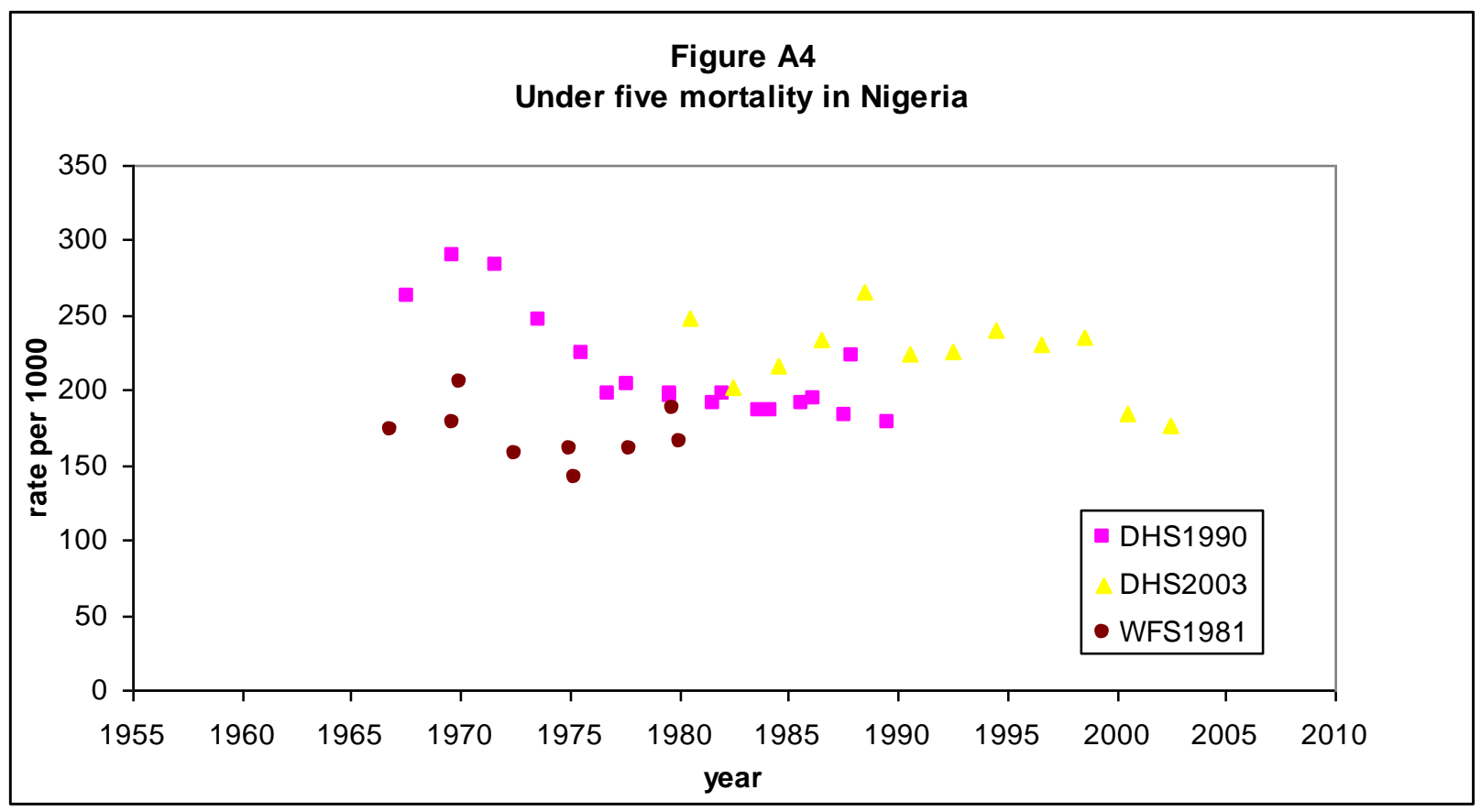




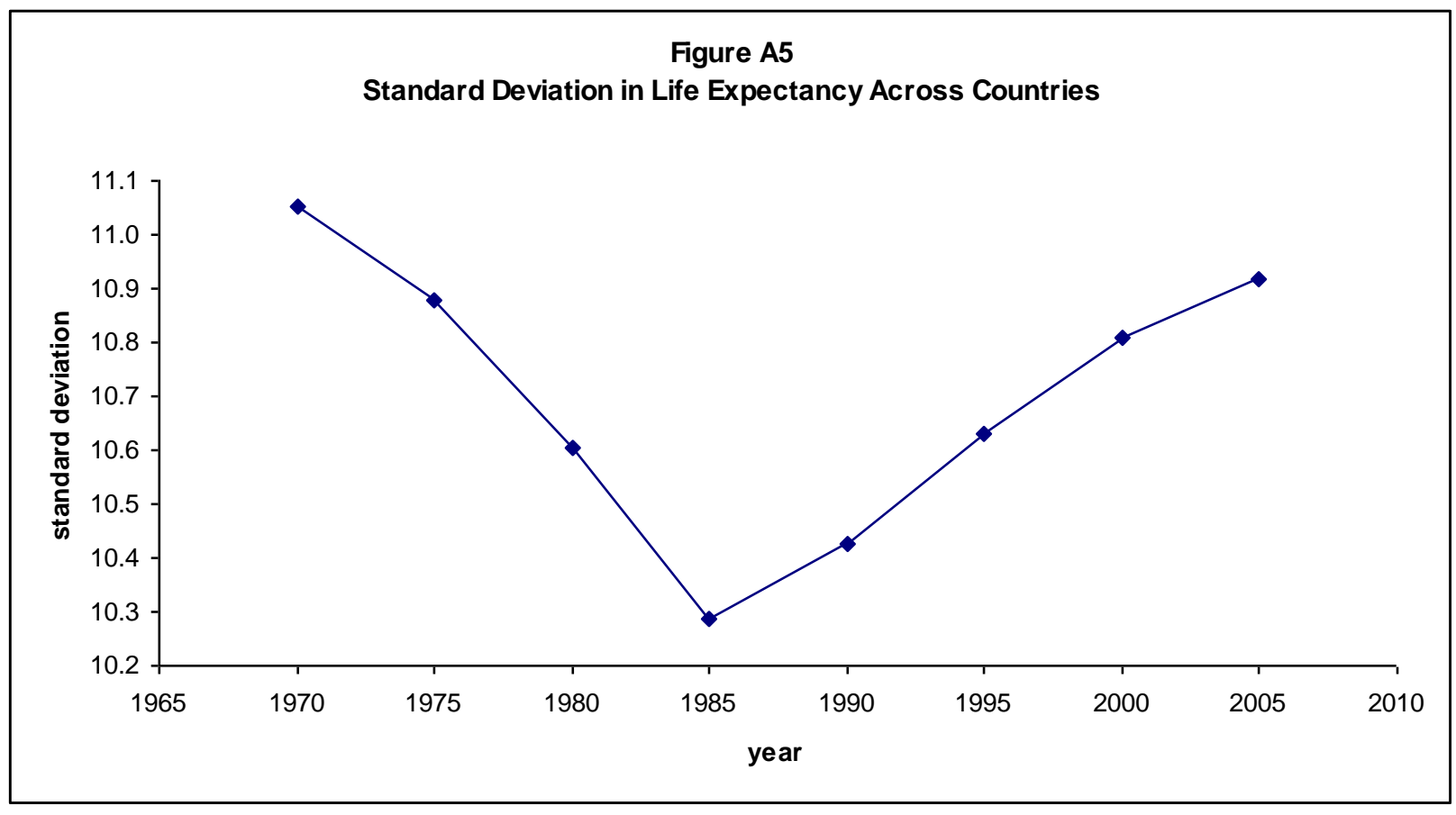




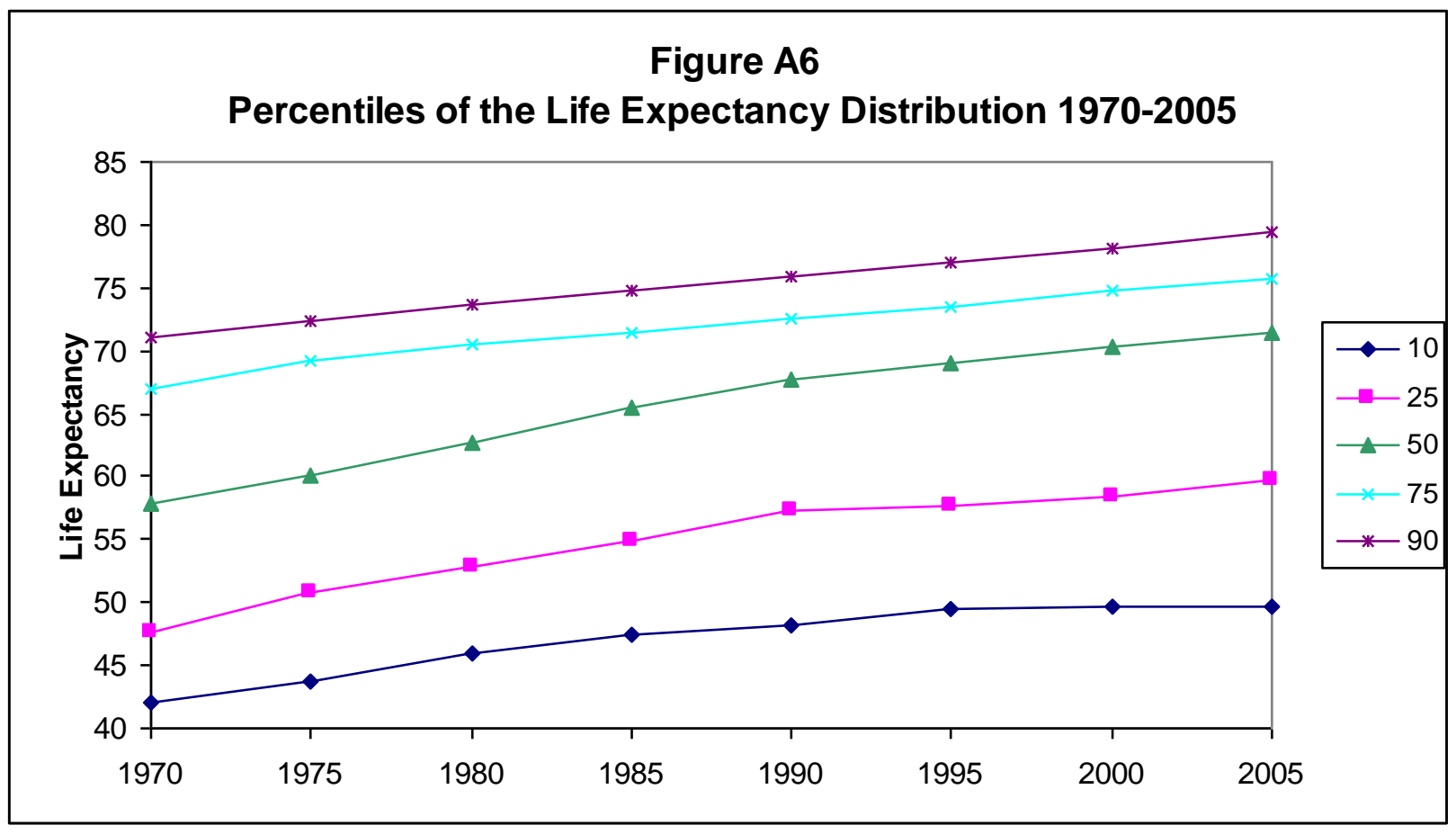




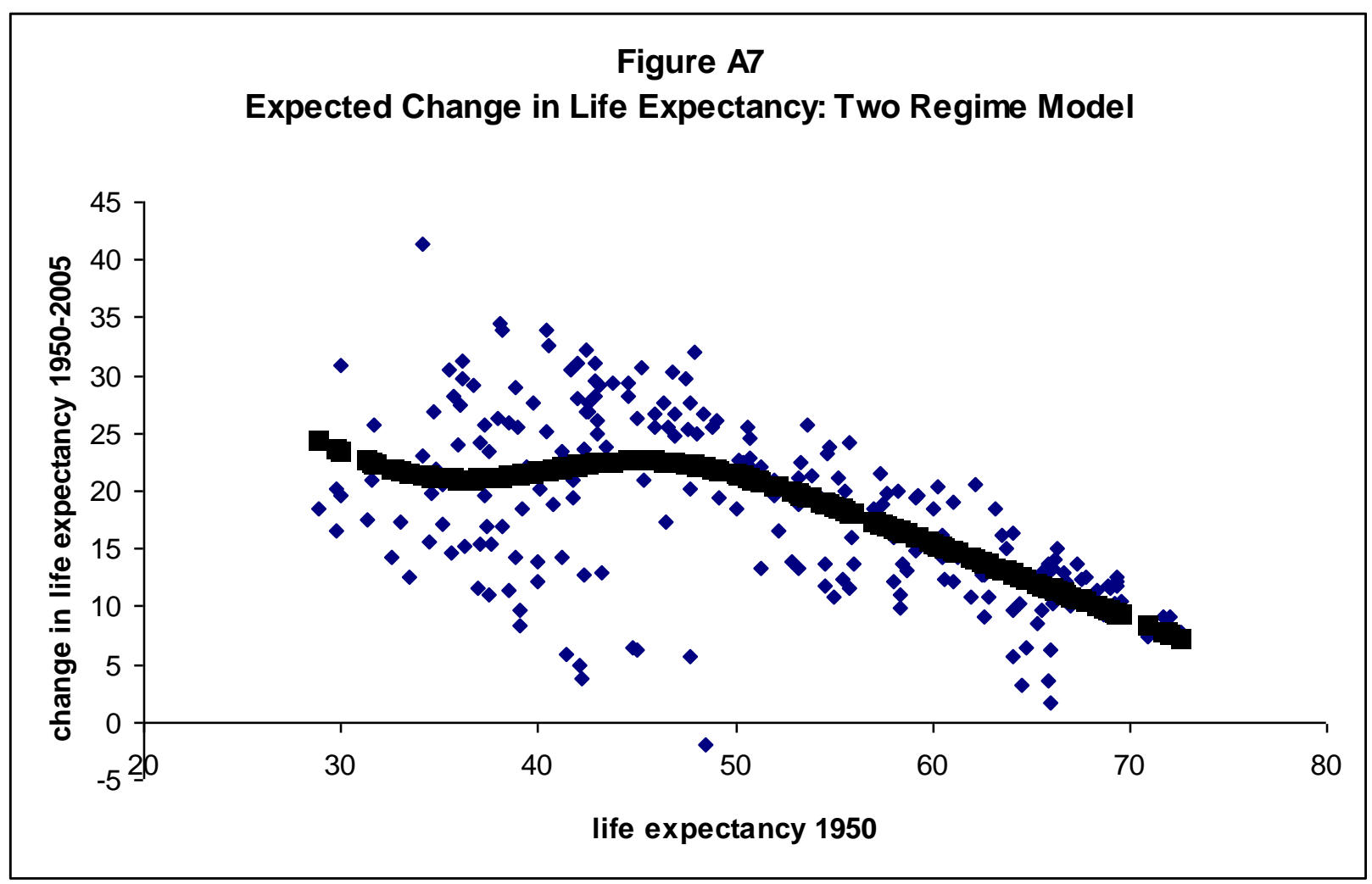

